\title{
AGAP3 and Arf6 Regulate Trafficking of AMPA Receptors and Synaptic Plasticity
}

\author{
Yuko Oku and Richard L. Huganir \\ Department of Neuroscience and Howard Hughes Medical Institute, Johns Hopkins University School of Medicine, Baltimore, Maryland 21205
}

\begin{abstract}
During NMDA receptor-mediated long-term potentiation (LTP), synapses are strengthened by trafficking AMPA receptors to the synapse through a calcium-dependent kinase cascade following activation of NMDA receptors. This process results in a long-lasting increase in synaptic strength that is thought to be a cellular mechanism for learning and memory. Over the past 20 years, many signaling pathways have been shown to be involved in the induction and maintenance of LTP including the MAPK cascade. However, the crucial link between NMDA receptors and the signaling cascades involved in AMPA receptor trafficking during LTP remains elusive. In this study, we aimed to identify and characterize NMDA receptor signaling proteins that link NMDA receptor activation to downstream signaling pathways that lead to trafficking of AMPA receptors. We have identified a novel NMDA receptor interacting signaling protein, AGAP3. AGAP3 contains multiple signaling domains, a GTPase-like domain, a pleckstrin homology domain, and an ArfGAP domain, and exists as a component of the NMDA receptor complex. In addition, we found that AGAP3 regulates NMDA receptor-mediated Ras/ERK and Arf6 signaling pathways during chemically induced LTP in rat primary neuronal cultures. Finally, knocking down AGAP3 expression leads to occlusion of AMPA receptor trafficking during chemically induced LTP. Together, AGAP3 is an essential signaling component of the NMDA receptor complex that links NMDA receptor activation to AMPA receptor trafficking.
\end{abstract}

\section{Introduction}

The human brain contains $10^{11}$ neurons, where a neuron contains $\sim 10^{4}$ synapses, allowing the formation of complex networks to transmit and store information. The storage of memory by these cellular networks is achieved through strengthening and weakening of specific synapses. NMDA receptor-dependent long-term potentiation (LTP) is a mechanism by which specific synaptic connections are strengthened between two cells by trafficking of AMPA-type glutamate receptors to the synapse (Malinow and Malenka, 2002). AMPA receptors are tetrameric ion channels composed of GluA1-A4 subunits that conduct the majority of the excitatory neurotransmission in the brain (Shepherd and Huganir, 2007). Synaptic trafficking of AMPA receptors is triggered by activation of NMDA receptors and kinase cascades including mitogen-activated protein kinase (MAPK) cascade

Received Jan. 24, 2013; revised May 28, 2013; accepted June 19, 2013.

Author contributions: Y.0. and R.L.H. designed research; Y.O. performed research; R.L.H. contributed unpublished reagents/analytic tools; Y.0. analyzed data; Y.O. wrote the paper.

This work was supported by funding from Howard Hughes Medical Institute and the National Institutes of Health. We gratefully acknowledge Dr. Scheffzek for SynGAP construct and Dr. Leahy for p $\alpha$ H vector. We thank M. Dai for neuronal "Banker" and glia cultures, R. Johnson for help in performing the yeast 2-hybrid screen, Y. Yu for maintaining the SynGAP knock-out mice colony, and L. Hamm for help in technical assistance. We also thank Dr. Diering and Dr. N. Hussain-Shuler for their help in preparation of hippocampal cells and all other Huganir lab members for helpful discussions and comments on this manuscript.

Under a licensing agreement between Millipore Corporation and The Johns Hopkins University, R.L.H. is entitled to a share of royalties received by the university on sales of products described in this article. R.L.H. is a paid consultant to Millipore Corporation. The terms of this arrangement are being managed by The Johns Hopkins University in accordance with its conflict of interest policies.

Correspondence should be addressed to Richard L. Huganir, Department of Neuroscience and Howard Hughes Medical Institute, Johns Hopkins University School of Medicine, Hunterian 1001, 725 North Wolfe Street, Baltimore, MD 21205. E-mail: rhuganir@jhmi.edu.

DOI:10.1523/JNEUROSCI.0341-13.2013

Copyright $\odot 2013$ the authors $\quad 0270-6474 / 13 / 3312586-13 \$ 15.00 / 0$
(Thomas and Huganir, 2004). Activation of the MAPK cascade, specifically Ras/ERK signaling pathway, is key to the induction of NMDA receptor-dependent LTP (English and Sweatt, 1996, 1997) and formation of some types of memory (Atkins et al., 1998; Blum et al., 1999; Selcher et al., 1999). However, the crucial link between activation of the MAPK cascades and AMPA receptor trafficking remains elusive.

In the brain, Ras/ERK and Rap/p38 signaling cascades are important for exocytosis and endocytosis of AMPA receptors, respectively (Zhu et al., 2002). Ras family small G-proteins play major roles in these signaling cascades by activating phosphorylation events that amplify the signal within the cell. Small G-proteins are active when they are GTP bound, and inactive when they are GDP bound. They are intrinsically poor GTPases and have greater affinity toward GDP than GTP, making activation a reversible but regulated process. To regulate small G-proteinmediated signaling cascades, GTPase activating proteins (GAPs) and GTP exchange factors (GEFs) are necessary to inactivate and activate these signaling cascades, respectively. To understand the link between NMDA receptor activation and signaling events that lead to LTP, this study aims to identify novel NMDA receptor interacting proteins that regulate small G-protein signaling and AMPA receptor trafficking.

To identify novel NMDA receptor interacting proteins that mediate NMDA receptor signaling and AMPA receptor trafficking, we have identified AGAP3 (also MRIP-1, CENTG3, and GGAP3). AGAP3 is a member of a family of proteins (AGAP 1-3) that contain a functional ArfGAP domain (Xia et al., 2003; Nie et al., 2005; Luo et al., 2012) and a GTPase-like domain (GLD; Qin et al., 2006; Soundararajan et al., 2007), suggesting they may have bifunctional enzymatic activities. Although few studies have fo- 
cused particularly on AGAP3, other AGAP proteins have been shown to regulate receptor trafficking and surface expression (Nie et al., 2003, 2005; Bendor et al., 2010; Chan et al., 2011). Here, we have shown that AGAP3 is a component of the NMDA receptor complex that regulates Arf6 and Ras/ERK signaling. Furthermore, knocking down AGAP3 expression leads to disruption of these signaling pathways and GluA1 trafficking during chemically induced LTP. These results demonstrate that AGAP3 is a novel NMDA receptor signaling protein that is involved in linking NMDA receptor signaling to AMPA receptor trafficking during LTP.

\section{Materials and Methods}

Yeast 2-hybrid screen. Yeast 2-hybrid screening was conducted as described previously (Xia et al., 1999) using a random-primed cDNA library from Sprague Dawley rat hippocampus cloned into pPC86 vector containing the GAL4 activation domain. The RasGAP domain of amino acids 319-647 of SynGAP $\alpha 1$ was cloned into Sal/Not sites of the PC97 vector that contains the GAL4 DNA binding domain as bait. The construct containing the bait and the cDNA library was transformed into PJ69 yeast cells. Positive clones were selected on plates lacking leucine, tryptophan, histidine, and adenine. Unique clones were identified using analytical restriction digest and subsequently amplified and confirmed by DNA sequencing.

Constructs and shRNAs. Full-length AGAP3 was cloned from a homemade randomly primed cDNA library from Sprague Dawley rat hippocampus and inserted into modified $\mathrm{pRK} 5$ and $\mathrm{p} \alpha \mathrm{H}$ vector (vector backbone provided by Leahy lab, Johns Hopkins School of Medicine, Baltimore, MD). ArfGAP mutation (R602K) and GTPase mutation (K139A S140N) was introduced by PCR. The human Arf6 construct used in this study was inserted into the modified $\mathrm{p} \alpha \mathrm{H}$ vector with a natural Kozak sequence or myc tagged in pRK5. The SynGAP- $\alpha 1$ construct was made as previously described (Kim JH et al., 1998). AGAP3 shRNA\#1 (forward primer: CCG CAC CAC CTG ATC GAG CGA ATC GCT CGA GCG ATT CGC TCG ATC AGG TCG TTT TTT G) was generated by annealing two complementary oligos into pLKO.1 between AgeI and EcoRI sites. GFPshRNA and AGAP3 shRNA\#2 (corresponding to forward primer: CCG GGC AGA CAT CTT GAT CCA GCA TCT CGA GAT GCT GGA TCA AGA TGT CTG CTT TTT G) in pLKO.1 was purchased from Sigma-Aldrich (Mission shRNA Consortium). shRNA sequences were subsequently cloned into pSuper vector (oligoengine) or modified pSuper vector with pCMV-Venus (Kamiya et al., 2005). Silent mutations at shRNA\#2 target region were made in AGAP3 rescue constructs using Splicing by Overhang Extension PCR (primer: AGA GTG TGC AGA CAT TCT AAT TCA GCA TGG GTG CC).

Antibodies. Rabbit polyclonal AGAP3 antisera JH6210 recognizing the $\mathrm{N}$ terminus (antigen: NFQAGGGQSPQQQSLAAPC) and C terminus JH6474 (antigen: KEPANGTNP SAELHRSPSIL) were generated at Covance and purified in-house. Rabbit polyclonal antibody against green fluorescent protein (GFP) recombinant protein (JH4030), anti-c-myc mouse monoclonal antibody, and anti-GluA1 (rabbit JH4294 and 4.9D monoclonal mouse) were made in-house. SynGAP (JH2469), NR2A (JH6097 and JH5525), and NR2B (JH6100 and JH5523) antibodies were generated in-house as previously described (Kim JH et al., 1998; Hayashi et al., 2009). Anti-PSD95/SAP90 antibody (K28/43) and SAP102 (N19/2) was purchased from University of California Davis/National Institutes of Health (NIH) NeuroMab facility. Anti- $\alpha$-tubulin monoclonal antibody (clone\# B-5-1-2) was purchased from Sigma-Aldrich. Guinea pig antivGlut1 polyclonal antibody was purchased from Millipore. PhosphoERK T202/Y204 (E10) and pan-ERK (137F5) antibodies were purchased from Cell Signaling Technology. Anti-HA.11 (16B12) antibody was purchased from Covance. Mouse monoclonal anti-Arf6 (ARFAG) antibody was purchased from Abcam.

AGAP3 and SynGAP purification. SynGAP C2GAP domain was purified as previously described (Pena et al., 2008). AGAP3 GLD containing residues 123-294 was cloned into pPROEx-HT (Life Technologies). The vector was transformed into BL21(DE3) Rosetta Escherichia coli cells and grown overnight in $20 \mathrm{ml}$ of Circle Grow (MP Biomedicals). The result- ing culture was then inoculated into $1 \mathrm{~L}$ of Circle Grow until OD600 $=\sim 0.8$ at $37^{\circ} \mathrm{C}$. IPTG $(1 \mathrm{~mm})$ was used to induce expression in these cultures and stored shaking overnight at $15^{\circ} \mathrm{C}$. The cells were spun down and lysed using a microfluidizer in $50 \mathrm{~mm}$ phosphate buffer, $\mathrm{pH}$ 7.4, $300 \mathrm{~mm} \mathrm{NaCl}, 8 \mathrm{~mm} \beta$-mercaptoethanol, and $20 \mathrm{~mm}$ imidazole. The lysate was loaded onto HistrapFF (GE Life sciences) column and eluted using 0-500 mm imidazole linear gradient on AKTApurifier FPLC (GE Life Sciences). Fractions containing the protein were pooled and dialyzed overnight in $20 \mathrm{~mm}$ HEPES, $\mathrm{pH} 7,150 \mathrm{~mm} \mathrm{NaCl}$, and $8 \mathrm{~mm}$ $\beta$-mercaptoethanol with purified recombinant His-tagged TEV protease to cleave the His-tag. The dialyzed product was then run on the Histrap FF again and flowthrough was collected containing the untagged GTPase domain. The protein was diluted twofold with $20 \mathrm{~mm}$ Tris- $\mathrm{Cl}, \mathrm{pH}$ 7, loaded onto a monoQ (GE Life Sciences) column, and eluted by using a $0-100 \%$ linear gradient of buffer B (20 mm Tris-Cl, pH 7, $500 \mathrm{~mm} \mathrm{NaCl})$ over 20 column volumes. The fractions containing pure protein were collected and dialyzed three times in $20 \mathrm{~mm}$ HEPES, pH 7.5, $50 \mathrm{~mm} \mathrm{NaCl}$, $10 \mathrm{~mm}$ EDTA, and $8 \mathrm{~mm} \beta$-mercaptoethanol. The protein was concentrated to $\sim 5 \mathrm{mg} / \mathrm{ml}$ and flash frozen in small aliquots for use.

In vitro GTPase assay. Purified GLD of AGAP3 (50 nM) was used in reaction buffer containing $50 \mathrm{~mm}$ Tris-Cl, $\mathrm{pH} 7,4 \mathrm{~mm} \mathrm{MgCl}_{2}, 4 \mathrm{~mm}$ dithiothreitol (DTT), and $0.02 \%$ NP-40 with $15 \mu \mathrm{Ci}$ of ${ }^{32} \mathrm{P}-\alpha \mathrm{GTP}$ 3000Ci (111TBq)/mmol $10 \mathrm{mCi} / \mathrm{ml}$ (PerkinElmer). SynGAP C2GAP domain $(1 \mu \mathrm{M})$ was added to indicated reactions. The reaction times were quenched by adding equal volume of Quench Buffer containing $20 \mathrm{~mm}$ DTT, 2\% SDS, and $20 \mathrm{~mm}$ EDTA. The reactions were then spotted on Baker-flex-coated PEI-F Cellulose TLC plates (J.T. Baker), and $1 \mathrm{M} \mathrm{LiCl}_{2}$ was used to separate GDP and GTP spots on the TLC plate. Densitometry was used to determine signals from radiolabeled GDP and GTP and to calculate fraction hydrolyzed per lane. Fraction hydrolyzed $=[\mathrm{GDP}] /$ total $([\mathrm{GTP}]+[\mathrm{GDP}])$.

Transfection and immunoprecipitation in HEK293T cells. Transfection was performed in HEK293T cells using calcium phosphate coprecipitation for 1-1.5 d. Cells were lysed in lysis buffer containing 25 mM HEPES, pH 7.4, $100 \mathrm{~mm} \mathrm{NaCl}, 1 \%$ Triton X-100, 0.5\% deoxycholic acid, $0.1 \%$ SDS, and $1 \mathrm{~g} / \mathrm{ml}$ leupeptin, $0.1 \mathrm{~g} / \mathrm{ml}$ aprotinin, $1 \mathrm{~g} / \mathrm{ml} \mathrm{PMSF}$, and $1 \mathrm{~g} / \mathrm{ml}$ pepstatin. Monoclonal anti-c-myc antibody ( $2 \mu \mathrm{l}$; home-made ascites) was used per reaction. Cell lysate was solubilized for $30 \mathrm{~min}$ and centrifuged at $16,100 \times g$ for $15 \mathrm{~min}$. Immunoprecipitation was performed overnight at $4^{\circ} \mathrm{C}$ and washed three times with lysis buffer and resuspended in $2 \times$ SDS loading buffer.

Cortical neuronal cell culture, electroporation, and chemical LTP stimulation. Cortical neurons from embryonic day 18 (E18) rat pups of either sex were plated onto poly-L-lysine-coated dishes in NM5: Neurobasal growth medium (Invitrogen) supplemented with 2\% B27 (Invitrogen), 2 mM Glutamax (Invitrogen), $50 \mathrm{U} / \mathrm{ml}$ penicillin/streptomycin (PenStrep; Invitrogen), and 5\% donor equine serum (HyClone). One hour after plating, fresh NM5 was added to the neurons. At 3 to 4 days in vitro (DIV), neurons were treated with $5 \mu \mathrm{M}$ uridine and $5 \mu \mathrm{M}(+)$-5-fluor-2' -deoxyuridine in NM1 (Neurobasal growth medium supplemented with 2\% B27, 2 mm Glutamax, $50 \mathrm{U} / \mathrm{ml}$ PenStrep, and 1\% horse serum) for $3 \mathrm{~d}$. Every 3-4 DIV thereafter, half of the culture media was changed with glia-conditioned NM1 until 15 DIV. Electroporation in dissociated cortical culture was performed using a Rat Neuron Nucleofector kit according to manufacturer protocol (Lonza Group). Chemical LTP in cortical culture was induced by pre-incubating cortical cultures for 1-1.5 h in Artificial CSF (ACSF: 25 mm HEPES, pH 7.4, $124 \mathrm{~mm} \mathrm{NaCl}, 3 \mathrm{~mm} \mathrm{KCl}, 2 \mathrm{~mm} \mathrm{CaCl}, 2 \mathrm{~mm} \mathrm{MgCl}_{2}$, and $10 \mathrm{~mm}$ glucose) containing $1 \mu \mathrm{M}$ strychnine then replaced into magnesium-free ACSF containing $200 \mu \mathrm{m}$ glycine and $1 \mu \mathrm{M}$ strychnine for $5 \mathrm{~min}$.

Lentivirus preparation. A $15 \mathrm{~cm}$ tissue culture dish containing $70 \%$ confluent HEK293T cells was transfected with $15 \mu \mathrm{g}$ of shRNA in pLKO.1, $20 \mu \mathrm{g} \Delta 8.9$, and $5 \mu \mathrm{g}$ VSVG using LF2000 according to manufacturer's protocol for $6-8 \mathrm{~h}$. The medium was then replaced into DMEM containing 10\% fetal bovine serum (HyClone) and 1\% PenStrep (Invitrogen). Virus was collected on 2 and $3 \mathrm{~d}$ post-transfection. The collected supernatant containing the virus was briefly spun at $1000 \mathrm{rpm}$ and filtered through a $0.45 \mu \mathrm{m}$ filter. Resulting virus mixture was spun at $25 \mathrm{k}$ at $4^{\circ} \mathrm{C}$ for $2 \mathrm{~h}$ in an SW28 swinging bucket rotor in an ultracentrifuge 
(Beckman Coulter). The pellet containing the virus was resuspended into Neurobasal medium (Invitrogen) and frozen for future use.

Immunoprecipitation and active GTPase pull-down from cortical neurons. For immunoprecipitation, neuronal culture was lysed in lysis buffer, solubilized for $30 \mathrm{~min}$, and centrifuged at 16,100 $\times \mathrm{g}$ for $15 \mathrm{~min}$. Anti-AGAP3-N (JH6210; $2 \mu \mathrm{g})$ antibody was used per reaction. For control experiments, $5 \mu \mathrm{g}$ of peptide used to generate the antibody was added to the antibody/Sepharose bead mixture while coupling antibody to beads and during the immunoprecipitation overnight. Then the immunoprecipitation was washed three times with lysis buffer and resuspended in $2 \times$ SDS loading buffer. Small GTPase activity assays were performed according to the manufacturer's protocol (Thermo Scientific) with lysis buffer containing $25 \mathrm{~mm}$ HEPES, pH 7.4, $100 \mathrm{~mm} \mathrm{NaCl}, 1 \%$ Triton X-100, 0.5\% deoxycholic acid, $0.1 \%$ SDS, and $1 \mathrm{~g} / \mathrm{ml}$ leupeptin, $0.1 \mathrm{~g} / \mathrm{ml}$ aprotinin, $1 \mathrm{~g} / \mathrm{ml}$ PMSF, and $1 \mathrm{~g} / \mathrm{ml}$ pepstatin.

Immunoprecipitation from P2 fractions. Frontal cortex was removed from 3- to 4-month-old rats and placed in PBS containing $0.303 \mathrm{M} \mathrm{su}$ crose and EDTA-free protease inhibitor mixture tablet (Roche). Homogenate was created using a glass/Teflon dunce homogenizer. The homogenate was spun down at $1400 \times g$ for 10 min to remove cell debris. The remaining supernatant was then spun down again at $13,800 \times g$ for $10 \mathrm{~min}$. Then, the pellet was resuspended at $10-20 \mathrm{mg} / \mathrm{ml}$ in $10 \%$ DOC in $50 \mathrm{~mm}$ Tris, $\mathrm{pH} 8.5$, at $37^{\circ} \mathrm{C}$ and diluted 10 -fold into ice-cold $0.1 \%$ Triton $\mathrm{X}-100$ in $25 \mathrm{~mm}$ Tris-Cl, pH 7.4. The solubilized fraction was added to anti-NR2A (JH6097) or anti-NR2B (JH6100) antibody/Sepharose A bead mixture and incubated overnight. For peptide block control experiments, $5 \mu \mathrm{g}$ peptide antigen was added to antibody/Sepharose A bead mixture. The immunoprecipitation was then washed three times in $0.1 \%$ Triton $\mathrm{X}-100$ in 25 mm Tris-Cl, pH 7.4, and resuspended in $2 \times$ SDS buffer.

Hippocampal neuronal cell culture and transfection. Hippocampal neurons were isolated from E18 rat pups of either sex and plated onto poly-L-lysine-coated coverslips in cultured in Neurobasal medium (Invitrogen) with B27 (Invitrogen), $0.5 \mathrm{~mm}$ glutamine, and $12.5 \mu \mathrm{M}$ glutamate. Neurons were transfected in Neurobasal medium containing $0.5 \mathrm{~mm}$ glutamine using Lipofectamine 2000 for $1 \mathrm{~h} 18-19$ DIV. Post-transfection, neurons were placed back into growth medium and immunostained $24 \mathrm{~h}$ later.

Chemical LTP induction and immunostaining in hippocampal neurons. Surface GluR1 was live stained using home-made anti-GluR1 N-terminal monoclonal ascites antibody (4.9D). Total GluR1 was detected using anti-GluR1 C-terminal rabbit polyclonal antibody (JH4294). LTP was chemically induced by pre-incubating the neuronal culture in ACSF containing $0.5 \mu \mathrm{M}$ tetrodotoxin (TTX), $20 \mu \mathrm{M}$ bicuculline, and $1 \mu \mathrm{M}$ strychnine. Subsequently, neurons were exchanged into $\mathrm{Mg}^{2+}$-free ACSF with $200 \mu \mathrm{M}$ glycine, $0.5 \mu \mathrm{M}$ TTX, $20 \mu \mathrm{M}$ bicuculline, and $1 \mu \mathrm{m}$ strychnine for $5 \mathrm{~min}$ and allowed to recover in pre-incubation media for $10 \mathrm{~min}$. DLAPV $(100 \mu \mathrm{M})$ was added to stimulation media for APV conditions. Immediately thereafter, neurons were washed in ACSF briefly, live stained at $10^{\circ} \mathrm{C}$ for $15 \mathrm{~min}$, fixed with $4 \%$ paraformaldehyde, and permeabilized with $0.25 \%$ Triton X-100. Coverslips were then blocked for $1 \mathrm{~h}$ with $10 \%$ bovine serum albumin in PBS and incubated with primary antibody overnight. Neurons were then washed five times in PBS, and incubated with Alexa-conjugated secondary antibody (Jackson ImmunoResearch) for $1 \mathrm{~h}$. Coverslips were washed four times and mounted using Permafluor mounting solution (Thermo Scientific).

Image acquisition and data analysis. Flatbed scanner was used to scan Western blot film and signal intensities of the digital image were measured using ImageJ (NIH). Immunofluorescence images were collected with a $63 \times$ oil-immersion objective on a Zeiss LSM510 confocal microscope. Series of optical sections were collected at $0.38 \mu \mathrm{m}$ intervals, and maximal intensity projection was used for data analysis. Five to six secondary dendritic regions per cell were picked to analyze intensity measurements in the Venus channel. MetaMorph (MDS Analytical Technologies) was used to threshold the surface and total GluA1 to visualize individual puncta in control conditions. The same threshold requirements were used for each experimental set. The integrated intensities were divided by area of dendritic region to find the normalized intensities for surface NR2A channel for $30 \mu \mathrm{m}$ secondary dendrite. For surface/total measurements, integrated intensity of surface was divided by total integrated intensity for every region. All measurements were then normalized to control conditions and combined to get the final values.

Statistics. All statistics were performed using R statistical package ( R Development Core Team, 2008). Multiple comparisons were performed using one-way ANOVA and Tukey's HSD post hoc test. Student $t$ test was used for pairwise comparisons.

\section{Results}

\section{AGAP3 was identified as a SynGAP interactor}

In the brain, Ras/ERK and Rap/p38 signaling cascades have been shown to be crucial signaling processes for NMDA receptordependent exocytosis and endocytosis of AMPA receptors, respectively (Zhu et al., 2002). SynGAP is a component of the NMDA receptor complex, and is highly enriched at excitatory synapses (Chen et al., 1998; Kim et al., 1998). SynGAP contains a Ras GTPase activating protein domain (RasGAP) and plays an important role in linking NMDA receptors to Ras/ERK (Komiyama et al., 2002; Kim et al., 2005; Rumbaugh et al., 2006) and Rap/p38 cascades (Krapivinsky et al., 2004; Pena et al., 2008). To determine novel components of the NMDA receptor signaling complex, we performed a yeast 2-hybrid screen of rat hippocampal cDNA library using SynGAP's RasGAP domain as bait. We screened $\sim 3.2$ million colonies, which yielded 15 unique cDNA inserts. The most abundant of these unique colonies (7/ 15) were cDNA inserts that encoded the GLD of AGAP3. AGAP3 has a GLD, pleckstrin homology domain $(\mathrm{PH})$, ArfGAP domain, ankyrin repeats, and a putative type-I PDZ ligand at its extreme $\mathrm{C}$ terminus. Different prey cDNAs obtained from the screen encompassed the entire GLD domain of AGAP3 (Fig. 1A). To test whether AGAP3 can interact with SynGAP protein we transfected HEK293T cells with myc-tagged SynGAP and HA-tagged AGAP3. AGAP3 coimmunoprecipitated with SynGAP protein suggesting that AGAP3 and SynGAP interact (Fig. 1B). SynGAP has a GAP domain structurally similar to RasGAP domains (Pena et al., 2008), which is important for its ability to regulate the trafficking of AMPA receptors (Rumbaugh et al., 2006). AGAP3 GTPase domain is structurally similar to H-Ras (Nedyalkova et al., PDB ID: 3IHW) with a sequence identity/similarity of $27 \% / 46 \%$ to H-Ras using ClustalW (Thompson et al., 1994). To determine whether SynGAP has GAP activity toward AGAP3 GTPase domain we purified recombinant AGAP3 GLD and C2-RasGAP domain from SynGAP, which has been shown to have RapGAP activity in vitro (Pena et al., 2008). With the addition of SynGAP RasGAP domain to AGAP3 GLD, we saw an increase in AGAP3 GTPase activity (Fig. 1C). This finding suggests that AGAP3 and SynGAP interact directly and that SynGAP regulates AGAP3 GTPase activity. To determine whether AGAP3 and SynGAP exist in a complex in vivo, AGAP3 was immunoprecipitated from primary cortical cultures. SynGAP coimmunoprecipitated with AGAP3, suggesting that they do exist in the same protein complex in the brain (Fig. 1D).

\section{AGAP3 is found at postsynaptic sites in the adult brain}

AGAP3 has at least three splice variants. The AGAP3 gene encodes a $\sim 98 \mathrm{kDa}$ full-length protein, a $\sim 58 \mathrm{kDa}$ protein found in NCBI EST database (accession: NM_001108616.1), and a $\sim 43$ $\mathrm{kDa}$ protein CRAM ([CRMP-5])-associated GTPase (CRAG; Qin et al., 2006). The multidomain structure of AGAP3 is split among these splice variants, suggesting a different physiological function for each of the splice variants (Fig. 2A). To determine which AGAP3 isoform may be important for synaptic function, we first wanted to identify which splice variants of AGAP3 are present at synaptic sites in the adult brain. Western blot of various tissue samples show that AGAP3 and CRAG are found in testes, 
A

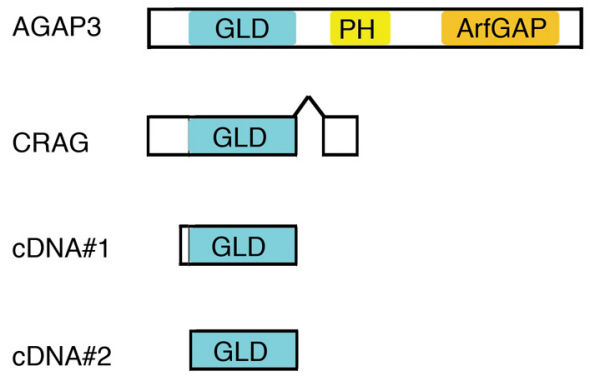

C

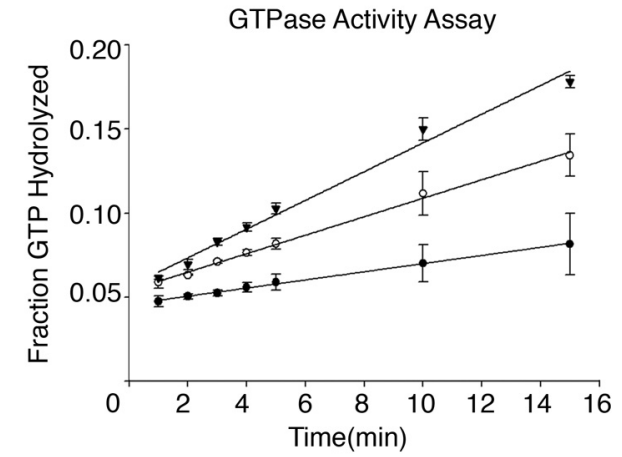

B

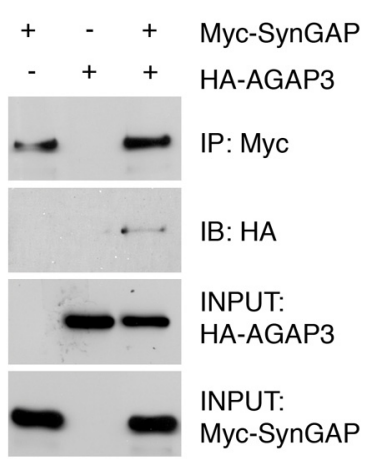

D

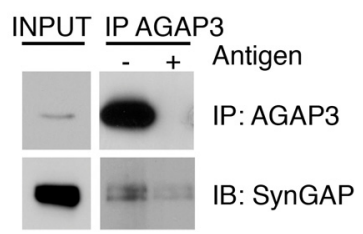

NR2A and NR2B from P2 brain fractions. In agreement with previous studies PSD95 and SynGAP coimmunoprecipitated with both NMDA receptor subunits (Kim JH et al., 1998; Kim MJ et al., 2005). Interestingly, AGAP3 (98 kDa band) coimmunoprecipitated with the NR2A but not NR2B subunit (Fig. 3A). Because AGAP3 contains multiple signaling domains ( $\mathrm{PH}$ domain, GTPase domain, and ArfGAP domain) and interacts with the NMDA receptor, we investigated if AGAP3 regulates NMDA receptor-dependent signaling. To examine NMDA receptor-dependent signaling downstream of AGAP3, we used two different shRNAs to knock down AGAP3 and its variants (Fig. 3B,C). By using glycine to stimulate primary cortical cultures, we observed increases in phospho-ERK signal that can be blocked by the NMDA receptor antagonist, APV, verifying that this increase in phosphoERK signal is NMDA receptor dependent. This change in phospho-ERK signal is not due to electroporation of dissociated neurons because we did not observe differences between control vector and mock electroporated or unelectroporated controls (data not shown). However, AGAP3 knockdown with both shRNAs dramatically decreased ( $\sim 4$-fold) the observed increase in phospho-ERK signal with glycine stimulation compared with control (Fig. 3D). Although similar effects were seen with both shRNAs, knockdown

sGure 1. AGAP3 was identified as a SynGAP interactor. A, Diagram of interacting AGAP3 CDNA clones identified from a yeast 2 hybid screen using SynGAP GAP domain as bait. The clones identified in the screen contain GLD in AGAP3 and CRAG. $\boldsymbol{B}$, Immunoprecipitation (IP) with anti-myc antibody was performed from myc-SynGAP and HA-AGAP3-transfected HEK293T cells IB, immunoblot. C, In vitro GTPase activity assay using purified recombinant SynGAP RasGAP domain and AGAP3 GLD was performed. The graph plots the ratio of GDP/(GTP + GDP) ${ }^{32}$ Psignal overtime. Error bars are standard error of mean from three experiments. $\nabla, A G A P 3 G L D$ with SynGAP's RasGAP domain; $\bigcirc$, AGAP3 GLD domain only; and , heat-inactivated AGAP3 GLD only. $n=3$. D, AGAP3 was immunoprecipitated (IP) from cortical cultures with and without peptide antigen using anti-AGAP3 antibody. IB, immunoblot.

lung, and brain (Fig. 2B). An anti-AGAP3 antibody that recognizes the $C$ terminus showed a similar tissue distribution of the 98 and $58 \mathrm{kDa}$ variants (data not shown). This result confirms that AGAP3 is present in the brain. Next, AGAP3 was detected on subcellular fractions from brain. Using antibodies targeted against either AGAP3 $\mathrm{N}$ terminus or $\mathrm{C}$ terminus, we were able to detect all three splice variants of AGAP3. AGAP3 and CRAG were both enriched in the PSDI, II, and III fractions; whereas, the 58 $\mathrm{kDa}$ variant detected by the C-terminal antibody was excluded from synaptic fractions (Fig. 2C). Finally, to determine whether AGAP3 is expressed in adult brain, we examined AGAP3 expression during development. AGAP3 expression peaks at postnatal day 7-15 (P7-P15), but is expressed into the adult. In contrast, CRAG expression increases gradually from P15 (Fig. 2D). To confirm that AGAP3 is present at postsynaptic sites as shown in the subcellular fractionation blot, endogenous staining was done in Banker cultures at 21 DIV using the AGAP3 N-terminal antibody. Anti-AGAP3 signal overlapped primarily with the postsynaptic marker PSD95 rather than the presynaptic marker vGlut, suggesting that AGAP3 and CRAG have a postsynaptic localization (Fig. 2E). Specificity of AGAP3 staining was confirmed by loss of signal with transfection of shRNA\#2 to knock down the expression of AGAP3 in dissociated hippocampal cultures (Fig. $2 F$ ). Together, these data suggest that AGAP 3 is present at postsynaptic sites in the adult brain.

\section{AGAP3 is a component of the NMDA receptor signaling complex}

To determine whether AGAP3 is a component of the NMDA receptor complex, we immunoprecipitated NMDA receptor subunits

efficiency of shRNA\#2 was greater than shRNA\#1 (Fig. 3C). Furthermore, shRNA\#1 knocks down AGAP3 splice variant, CRAG, also found in the PSD (Fig. 2C). Therefore, further experiments were performed using shRNA\#2. Since AGAP3 knockdown closely resembles the Ras/ERK signaling deficit observed in SynGAP knock-out mice, we predicted that our observations are the result of perturbing SynGAP function. To test this hypothesis, we knocked down AGAP3 expression in SynGAP knock-out cultures and observed Ras/ERK signaling during glycine-induced LTP (Fig. 3E). Consistent with published data, SynGAP knockout mice exhibit decreased Ras/ERK signaling compared with wild-type (WT) littermate cultures after chemically induced LTP. However, the loss of AGAP3 expression in both WT and SynGAP knock-out cultures decreased glycine-induced increases in phospho-ERK compared with control conditions (Fig. 3E). This experiment suggests that the effects of AGAP3 knockdown are not completely dependent of SynGAP function. These observed deficits cannot be explained by decreased expression of synaptic proteins since knockdown of AGAP3 with shRNA\#2 did not alter total expression of the NMDA receptor subunit NR1, AMPA receptor subunit GluA1, SynGAP, or ERK. Although, a slight increase in basal phospho-ERK and PSD95 was observed (Fig. $3 F$ ). These results further support proteins and receptors that are important for this signaling pathway remains intact. Together, these data suggest that the $98 \mathrm{kDa} \mathrm{AGAP} 3$ is a component of NMDA receptor signaling complex and regulates NMDA receptor-dependent Ras/ERK signaling. 
A

\begin{tabular}{|l|l|l|}
\hline GLD & PH & ArfGAP \\
\hline AGAP3
\end{tabular}

C

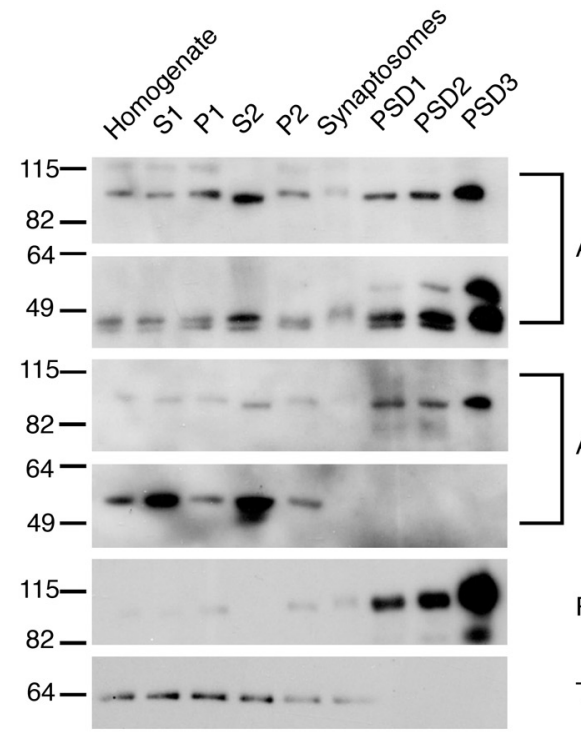

E
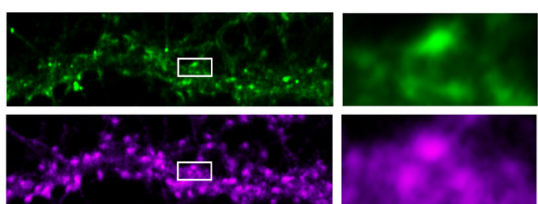

AGAP3-N

AGAP3-N

PSD95

Tubulin

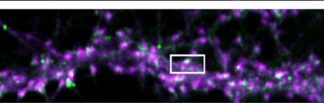

F
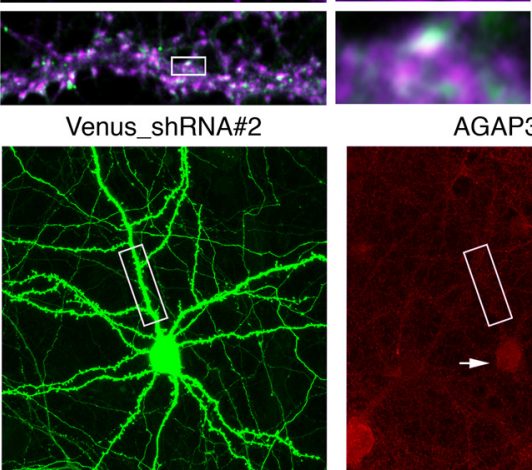

PSD95
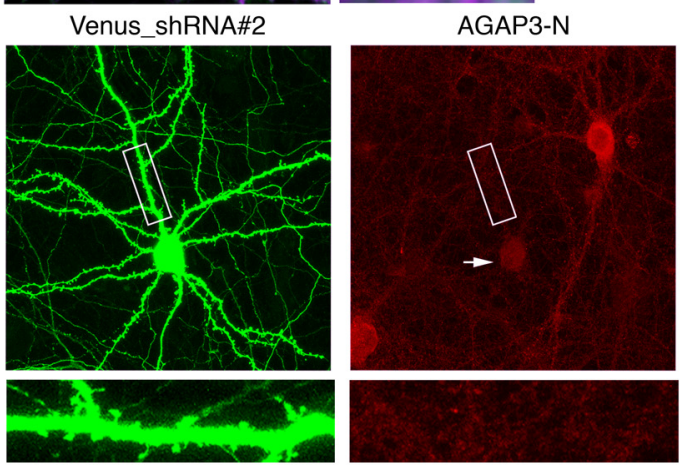

B

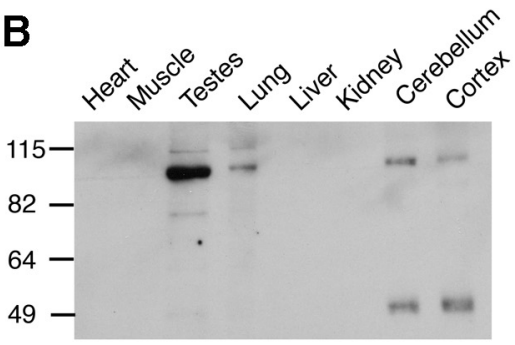

AGAP3

CRAG

D

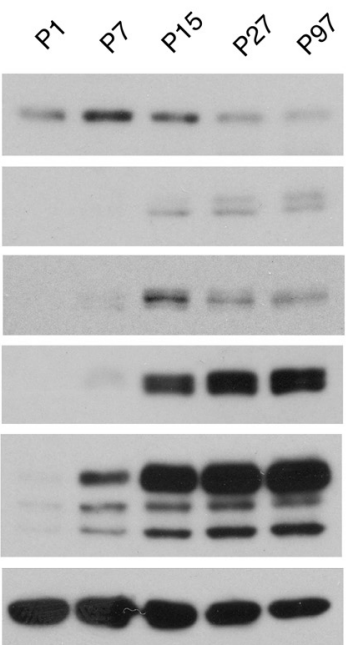

AGAP3-N

CRAG

SAP102

SynGAP

PSD95

Tubulin
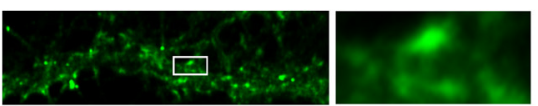

AGAP3-N
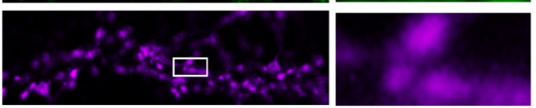

vGlut
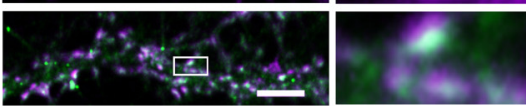

Merge

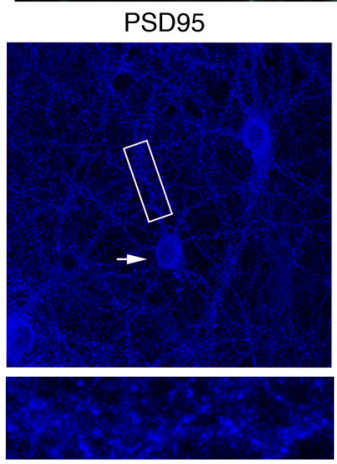

Figure 2. AGAP3 is found at postsynaptic sites in the adult brain. A, A diagram depicting AGAP3 splice variants and their domain structure. EST, expressed sequence tag found at NCBI database. $B$, AGAP3 and CRAG expression were detected in rat tissue homogenates using an antibody derived from the N terminus of AGAP3.C, AGAP3 and its splice variants were detected in subcellular fractionation of the adult rat brain . AGAP3-N, antibody derived from N terminus of AGAP3; AGAP3-C, antibody derived from C terminus of AGAP3. Fractions: S, supernatant; P, pellet; PSD, postsynaptic density. D, AGAP3 expression was detected in a developmental profile of rat brain homogenate using antibody derived against AGAP3 $N$ terminus. $E$, Representative dendritic and spine image from Banker culture costained with indicated antibodies at 21 DIV. Scale bar, $5 \mu \mathrm{m}$. F, AGAP3 staining in hippocampal cultures at 21 DIV with transfection of Venus_shRNA\#2 to knockdown AGAP3 expression. Scale bars: 50 and $10 \mu \mathrm{m}$.

AGAP3 regulates both Ras and Arf6 signaling

AGAP3 knockdown decreases NMDA receptor-dependent Ras/ ERK signaling. Furthermore, AGAP3 contains an ArfGAP domain and modification of Arf6 activity by knocking down expression of Arf6 GEF has been shown to abolish NMDA receptor-dependent
LTD (Scholz et al., 2010). Therefore, we tested whether AGAP3 regulates the Ras/ERK pathway or the Arf6 pathway. To do this, we knocked down the expression of AGAP3 and assessed the level of Ras and Arf6 activity under basal conditions using Active GTPase Pulldown kits (Thermo Scientific). To determine the specificity of this 
A

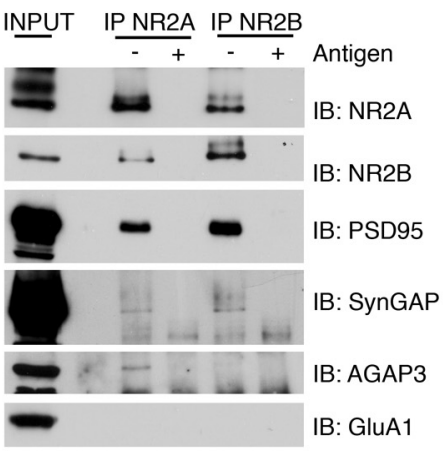

D
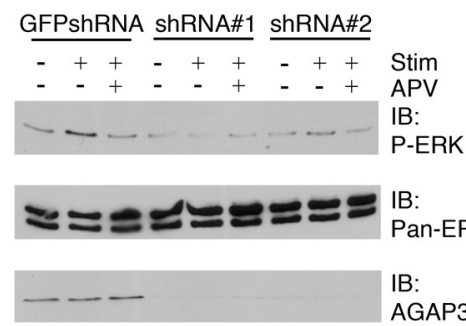

Normalized phospho-ERK2 with CLTP

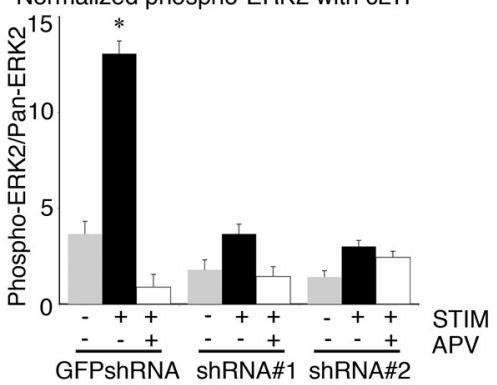

B

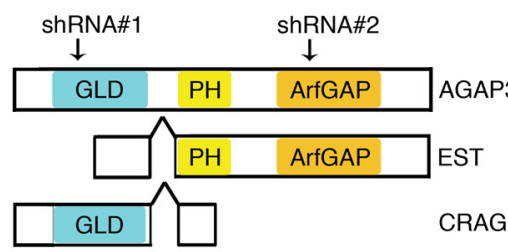

E

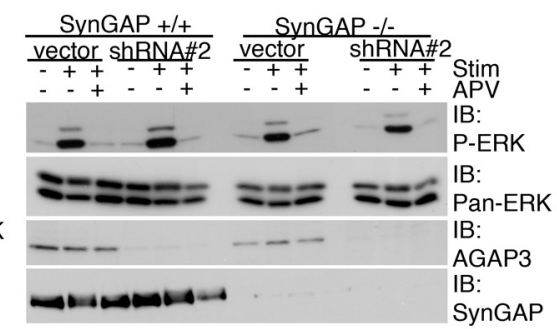

Normalized phospho-ERK2 with CLTP

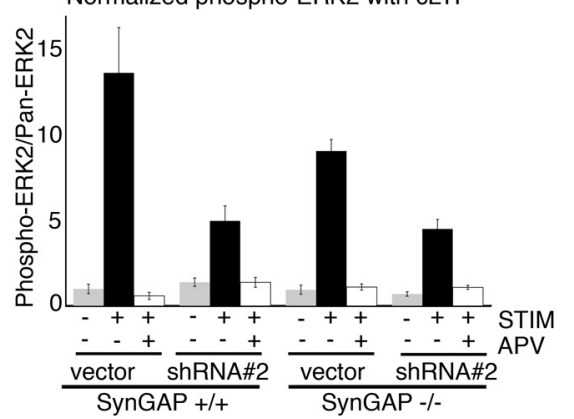

$\mathbf{F}$
C

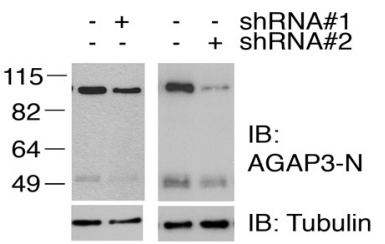

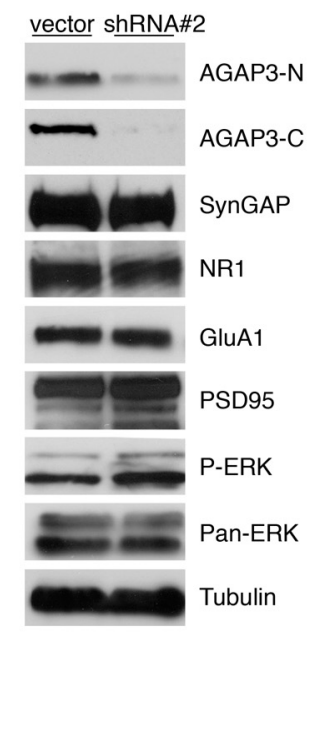

Figure 3. $A G A P 3$ is a component of the NMDA receptor signaling complex. $A, N R 2 A$ - and NR2B-subunits were immunoprecipitated (IP) in the presence and absence of peptide antigen from brain. IB, immunoblot. $B$, Schematic of AGAP3 domain structure indicates the location of the target sequence of the AGAP3 shRNAs. $C$, Representative expression of AGAP3 with electroporation of shRNA constructs\#1 and \#2. AGAP3-N, antibody derived against AGAP3 N-terminus. D, Top, Phospho-ERK signal was detected in shRNA\#1 and shRNA\#2 electroporated cortical cultures under unstimulated, chemical LTP stimulated, and chemical LTP stimulated with APV conditions. Bottom, Quantification of Phospho-ERK2 signal normalized to unstimulated GFPshRNA control. One-way ANOVA, $p=$ 3.71e-14, $n=6$ (unstim), 12 (stim), 6 (APV). Gray, unstimulated; black, stimulated; white, APV; ${ }^{*} p \leq 0.05$ after Tukey's HSD posthoc test. Error bars are standard error of mean. E, Top, Phospho-ERK signal detected after chemical LTP stimulation in SynGAP knock-out mice with and without AGAP3 knockdown. Bottom, Quantification of Phospho-ERK2 signal normalized to unstimulated vector control. One-way ANOVA, $p=6.0 \mathrm{e}-4, n=4$. Gray, unstimulated; black, stimulated; white, APV; ${ }^{p} p \leq 0.05$ after Tukey's HSD post hoc test. Error bars are standard error of mean. $\boldsymbol{F}$, Western blot of total protein expression with electroporation of shRNA\#2 in primary rat cortical neurons.

detection method we electroporated constitutively active and dominant-negative Ras and Arf6 in dissociated cortical cultures. Using our modified protocol, we pulled down constitutively active but not dominant-negative Ras and Arf6, confirming the specificity of the kit to detect active small G-proteins (data not shown). Following knockdown of AGAP3 we saw a significant increase in basal Ras activity $(1.58 \pm 0.20, n=3$; Student's $t$ test, $p=0.048)$ similar to what has been shown in SynGAP knock-out mice (Komiyama et al., 2002; Rumbaugh et al., 2006; Carlisle et al., 2008). In addition, there was a significant increase in basal Arf6 activity with knockdown of AGAP3 (1.64 $\pm 0.21, n=3$; Student's $t$ test, $p=0.039)$ consistent with AGAP3 having Arf6 GAP activity (Fig. $4 A$ ). To determine whether AGAP3 has Arf6 GAP activity, we tested AGAP3's ability to bind Arf6. Arf6 WT, GTP-binding active mutants (Q67L), or GDPbinding $(\mathrm{T} 44 \mathrm{~N})$ inactive mutants were cotransfected with AGAP3 and immunoprecipitated from HEK293T cells. AGAP3 bound strongly to GTP-binding Arf6 ${ }_{\mathrm{Q} 67 \mathrm{~L}}$ but not to GDP-binding Arf6 ${ }_{\mathrm{T} 44 \mathrm{~N}}$ (Fig. 4B). Together, these experiments suggest that AGAP3 acts as a
GAP toward Arf6. Overexpression of WT AGAP3 in primary cortical cultures significantly decreased active GTP-bound Ras (0.53 \pm $0.16, n=3$, Student's $t$ test, $p=0.041$ ) and Arf6 (Fig. $4 C ; 0.45 \pm 0.05$, $n=3$, Student's $t$ test, $p$ value $=0.0005$ ), suggesting that AGAP3 negatively regulates Arf6 and Ras. Finally, to determine the signaling domains within AGAP3 that regulate Arf6 and Ras signaling, we overexpressed point mutants of AGAP3 GTPase or ArfGAP domains in primary cortical cultures and investigated Arf6 and Ras activity. Overexpression of the ArfGAP mutant increased Arf6 activity compared with $\mathrm{WT}$ as expected. Interestingly, overexpression of the ArfGAP mutant also significantly increased Ras activity (Fig. $4 C, D)$. These observed data suggest that the AGAP3 ArfGAP domain regulates both Ras and Arf6 activity.

\section{AGAP3 regulates NMDA receptor-mediated Ras/ERK and Arf6 signaling during chemical LTP}

Induction of NMDA receptor-dependent LTP leads to an increase in Ras activity (Thomas and Huganir, 2004). Consistent 
with previous findings, we observed an NMDA receptor-dependent increase in Ras activity after 5 min of glycine stimulation. Interestingly, we also saw an NMDA receptor-dependent upregulation in Arf6 activity with the same stimulation (Fig. 5A). Considering AGAP3 regulates Arf6 and Ras activity, we investigated the effect of AGAP3 knockdown during glycine stimulation. We used shRNA\#2 to knock down AGAP3 and detected active Arf6 and Ras activity in unstimulated and stimulated conditions. Following knockdown of AGAP3, we observed a significant increase in basal Ras and Arf6 activity that occluded glycine-stimulated Ras (normalized within group, stimulated/unstimulated $=1.59 \pm$ 0.25(Scrambled), $0.70 \pm 0.37$ (shRNA\#2), Student's $t$ test, $p$ value $=0.024, n=3)$ and Arf6 activity (Fig. $5 B$; normalized within group, stimulated/unstimulated $=2.70 \pm$ 0.25(Scrambled), $0.61 \pm 0.11$ (shRNA\#2), Student's $t$ test, $p$ value $=0.0015, n=3)$. These data further suggest that AGAP3 is an activity-dependent signaling protein that negatively regulates Arf6 and Ras signaling pathways. To determine the signaling domain within AGAP3 that regulates NMDA receptor-dependent Ras/ERK signaling, we performed a molecular replacement experiment. To do this, we used shRNA\#2 to knockdown endogenous AGAP3 while at the same time driving the expression of shRNA-resistant WT AGAP3 or GTPase or ArfGAP mutants. Consistent with previous data, AGAP3 knockdown blocked the increase in phospho-ERK following glycine stimulation. The increase in phospho-ERK could be rescued by the expression of shRNA-resistant AGAP3 WT or ArfGAP mutant but not by the GTPase mutant (Fig. $5 C, D)$. However, we did not see rescue of the basal phospho-ERK increase that results from AGAP3 knockdown; although this was not statistically different from vector control.

\section{AGAP3 regulates AMPA receptor trafficking through the} ArfGAP domain

We have shown that AGAP3 regulates Ras and Arf6 activity. Ras is activated by NMDA receptors and is important for subsequent AMPA receptor trafficking (Zhu et al., 2002) while Arf6 is an important regulator of endosomal recycling from clathrin-independent endocytosis (Grant and Donaldson, 2009). Therefore, we hypothesized that AGAP3 may link NMDA receptor-mediated Ras signaling and AMPA receptor trafficking through Arf6. With lentiviral expression of shRNA\#2 and cell-surface biotinylation, we saw an increase in surface/total GluA1 in dissociated cortical cultures (data not shown). To test the signaling domain that is responsible for AMPA receptor trafficking, we performed additional molecular replacement experiments in rat hippocampal cultures and immunostained for GluA1. By live labeling GluA1 at $10^{\circ} \mathrm{C}$ using an antibody against the $\mathrm{N}$ terminus of the receptor, we were able to visualize surface
GST

Pull-Down

ShRNA\#2

IB: Ras

IB: Arf6

IB: AGAP3

IB: Tubulin

B

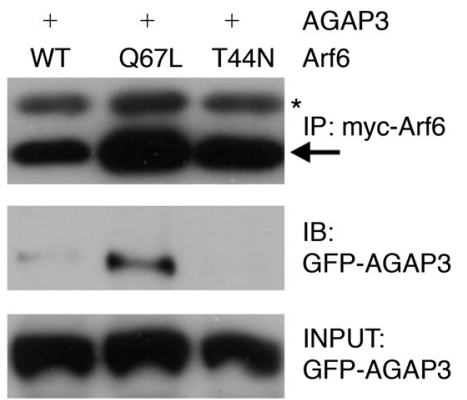

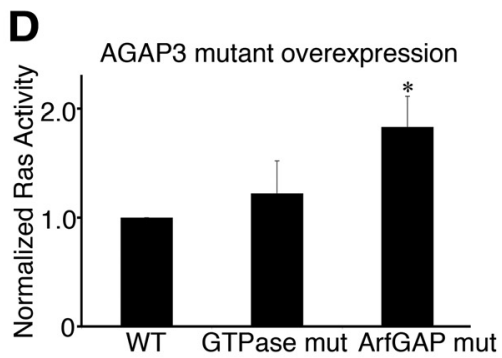

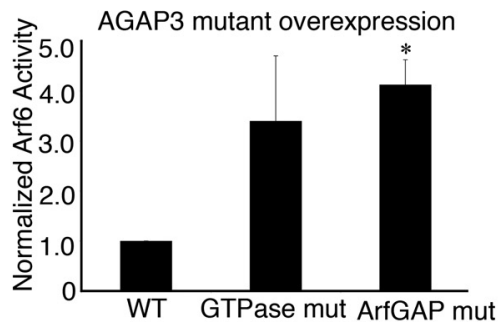

Figure 4. AGAP3 regulates both Ras and Arf6 signaling pathways. $\boldsymbol{A}$, Arf6 and Ras basal activity was detected using Active GTPase Pull-down kit (Thermo Scientific) with lentiviral expression of vector or shRNA\#2 in cortical neurons. IB, immunoblot. $\boldsymbol{B}$, tion of basal Ras and Arf6 activity after overexpression of AGAP3 WT and signaling domain point mutants (mut). One-way ANOVA $p=0.049, n=6$ (Ras); $p=0.042, n=5\left(\right.$ Arf6); ${ }^{*} p \leq 0.05$ after Tukey's HSD post hoc test. Error bars are standard error of mean.

GluA1. With knockdown of AGAP3, we saw an 20\% increase in surface/total GluA1 levels rescued with WT and GTPase mutant of AGAP3. However, the ArfGAP mutant failed to rescue the change in surface/total GluA1 (Fig. 6A,B). We also looked at surface/total GluA1 levels with overexpression of WT, GTPase mutant, and ArfGAP mutant and observed similar results (data not shown). In contrast to AMPA receptor staining, we did not observe statistically significant differences in surface NMDA receptor subunit NR2A levels between all conditions (Fig. 6C). Furthermore, increases in surface GluA1 observed with loss of AGAP3 expression correlated with the increased spine density (Figs. $6 A, 7 A$; vector $=1.00 \pm 0.029, n=$ 95 dendritic regions; shRNA\#2 $=1.17 \pm 0.035, n=110$ dendritic regions, Student's $t$ test, $p$ value $=0.00039$ ). Together, these data suggest AGAP3 regulates AMPA receptor trafficking through the ArfGAP domain.

Our results so far suggest that AGAP3 acts on AMPA receptor trafficking by controlling Arf6. Knockdown of AGAP3 led to an increase in Arf6 activity (Fig. 4A) and an increase in surface 
A

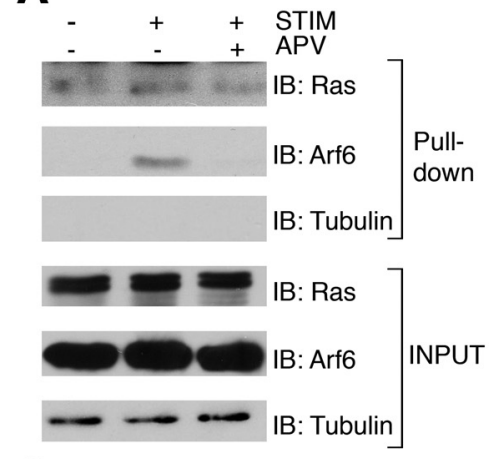

c

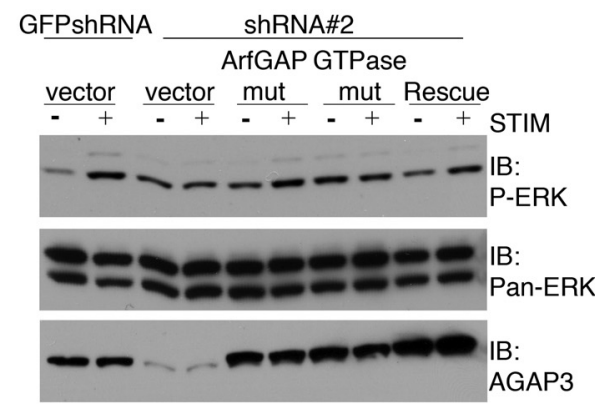

B

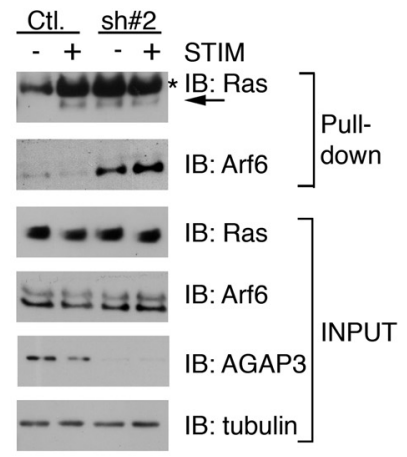

D

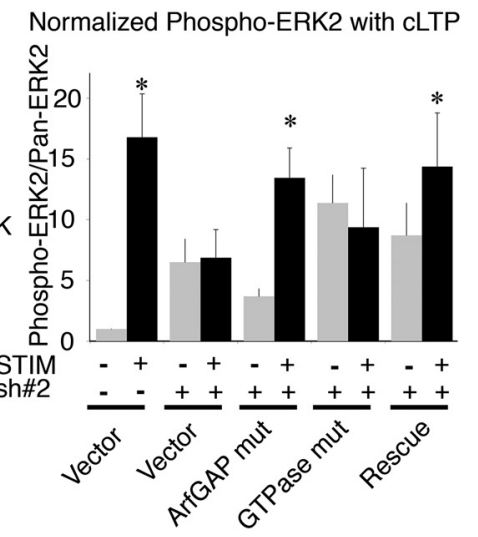

Figure 5. AGAP3 regulates NMDA receptor-mediated Ras/ERK and Arf6 signaling pathways during chemically induced LTP. $A$, Active Ras and Arf6 was detected using Active GTPase Pull-down and Detection kit (Thermo Scientific) from cortical cultures in unstimulated, chemical LTP stimulated or stimulated with APV conditions. IB, immunoblot. B, Active Ras and Arf6 were detected after chemical LTP stimulation in Scrambled (CtI.) or shRNA\#2 (sh\#2) electroporated cortical neurons with and without chemical LTP stimulation. Asterisk indicates nonspecific band present from addition of GST recombinant protein. Arrow indicates position of Ras protein. IB, immunoblot. C, Unstimulated and stimulated phospho-ERK2 signal after electroporation of AGAP3 shRNA\#2 and/or AGAP3 mutant (mut) rescue constructs. IB, immunoblot. D, Quantification of phopho-ERK2 signals are normalized to GFPshRNA unstimulated control. One-way ANOVA, $p=0.0028, n=3$. Gray, unstimulated; black, stimulated. ${ }^{*} p \leq 0.05$ after Tukey's HSD post hoc test compared with unstimulated GFPshRNA control. Error bars are standard error of mean.

GluA1 targeting (Figs. 6, 7). Consistent with this data expression of dominant-negative GDP-bound $\mathrm{Arf6}_{\mathrm{T} 44 \mathrm{~N}}$ alone decreased surface GluA1 and completely blocked the effect of AGAP3 shRNA (Fig. 7).

\section{AGAP3 regulates trafficking of GluA1 during chemical LTP} AGAP3 regulates basal and activity-dependent Ras/ERK and Arf6 signaling (Fig. 5). AGAP3 also regulates basal GluA1 trafficking (Fig. 6). To determine whether AGAP3 is important for activitydependent GluA1 trafficking, we chemically induced LTP in dissociated hippocampal culture using an established glycine treatment protocol (Liao et al., 2001; Lu et al., 2001). Similar to previous reports, we saw a $\sim 27 \%$ increase in surface/total GluA1 10 min after cLTP induction in control conditions. The NMDA receptor antagonist, APV, blocks this increase in surface GluA1 (data not shown). However, using shRNA\#2 to knockdown AGAP3 expression, we saw a significant increase in basal surface/total GluA1 that completely occluded the glycine-induced increase in surface GluA1. Consistent with previous experiments that the AGAP3 ArfGAP domain is important for basal trafficking of GluA1, cotransfection of shRNA\#2 with the ArfGAP mutant insensitive to shRNA-mediated knockdown also occluded the increase in surface/total GluAl. Additionally, cotransfection of the GTPase rescue mutant also blocked changes in surface/total GluA1 with chemical LTP stimulation. Finally, basal and stimulated surface/total GluAl is rescued by the expression of shRNA-resistant AGAP3 WT (Fig. 8A,B). These results show that AGAP3 is important for trafficking of GluA1 during cLTP.

\section{Discussion}

To identify essential signaling mechanisms linking NMDA receptor activation to AMPA receptor trafficking, we identified a novel NMDA receptor signaling protein AGAP3. We identified AGAP3 through a yeast 2-hybrid screen using SynGAP's RasGAP domain as bait. Similar to SynGAP's synaptic function (Kim MJ et al., 2005; Rumbaugh et al., 2006), AGAP3 is a component of the NMDA receptor complex that regulate Ras/ERK signaling and AMPA receptor trafficking. The similarity in AGAP3 and SynGAP function suggests that they likely play roles in the same signaling pathway. In this study, we have elucidated the mechanism of NMDA receptor signaling further by showing that AGAP3 regulates Arf6 and Ras/ERK signaling during chemical LTP. Furthermore, we show that AGAP3 is important for regulating AMPA receptor trafficking during chemical LTP. Last, we separated AGAP3's role in activitydependent AMPA receptor trafficking from basal trafficking of AMPA receptors within its signaling domains. We found that AGAP3 GTPase domain regulates Ras/ERK signaling previously reported to be essential for activity-dependent trafficking of AMPA receptors (Zhu et al., 2002); whereas, AGAP3 ArfGAP domain regulates basal trafficking of AMPA receptors. Together, we conclude that AGAP3 is an essential component of the NMDA receptor signaling complex that serves to link NMDA receptor activation to AMPA receptor trafficking.

AGAP3 has multiple splice variants. The bifunctional nature of AGAP3 signaling domains complicates assessing the function of one particular splice variant. To confirm that we are indeed assessing the function of AGAP3, we performed several controls. First, we showed that both hairpins dramatically reduce NMDA receptor-dependent increases in phospho-ERK. Second, we chose shRNA\#2 because the ArfGAP domain containing splice variant is excluded from synaptic fractions unlike CRAG. Last, in all functional studies, a rescue experiment was performed using a mismatched rescue construct to the target shRNA site to ensure specificity of not just the hairpin but of AGAP3 function. In this way, we believe that the deficits we observed in our experiments are the result of AGAP3 knockdown.

We observed that AGAP3 preferentially binds to NR2A over NR2B subunit of the NMDA receptor, suggesting that AGAP3 participates in subunit specific signaling. NMDA-type glutamate receptors are tetrameric receptors composed of predominantly NR1 subunits associated with NR2A or NR2B subunits in the adult prefrontal cortex (Luo et al., 1997). A unique structural 
A
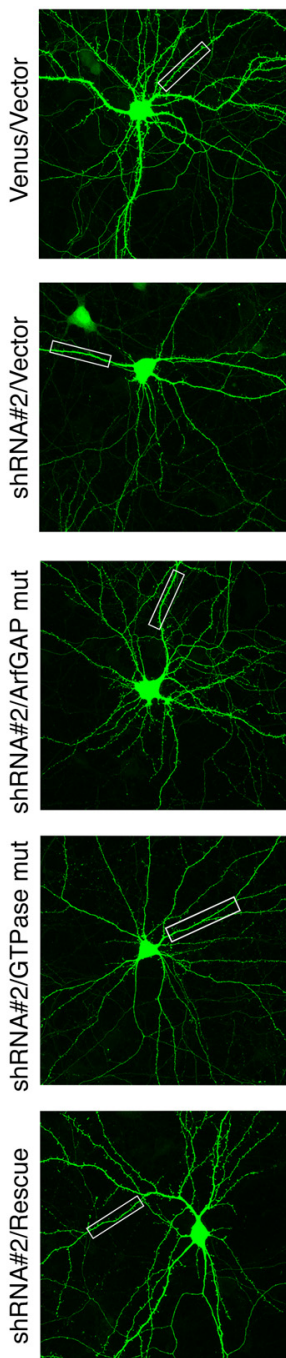

B

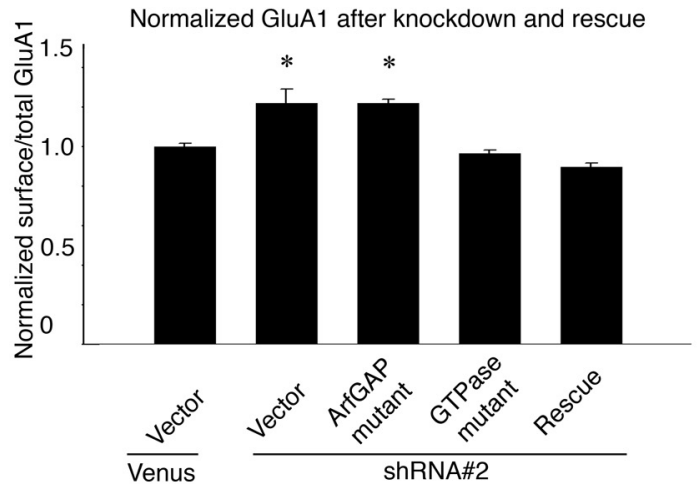

Surface GluA1
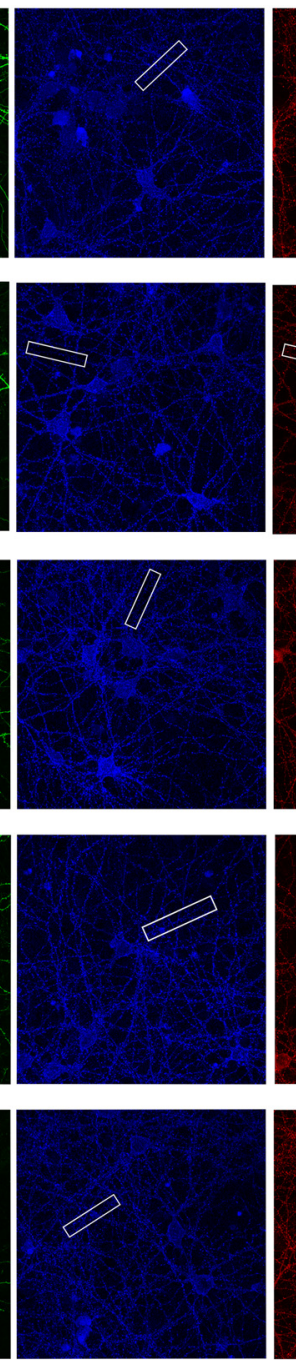

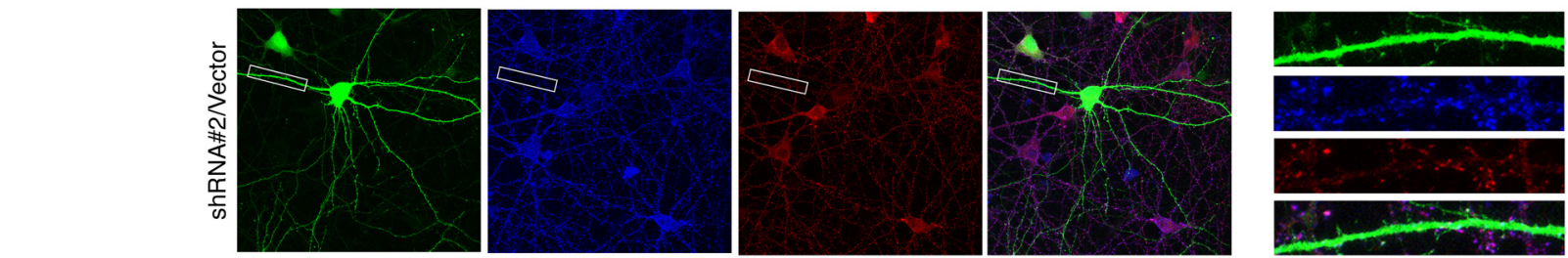

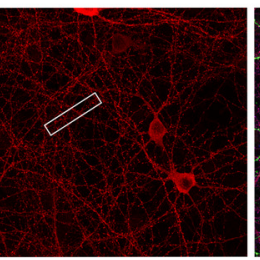

C

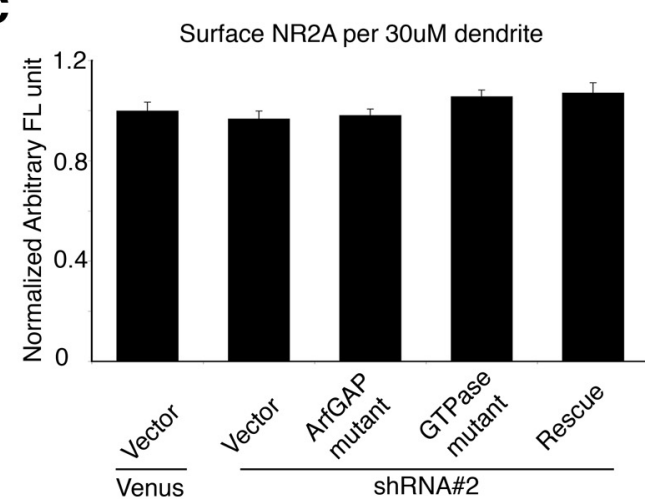

Merge
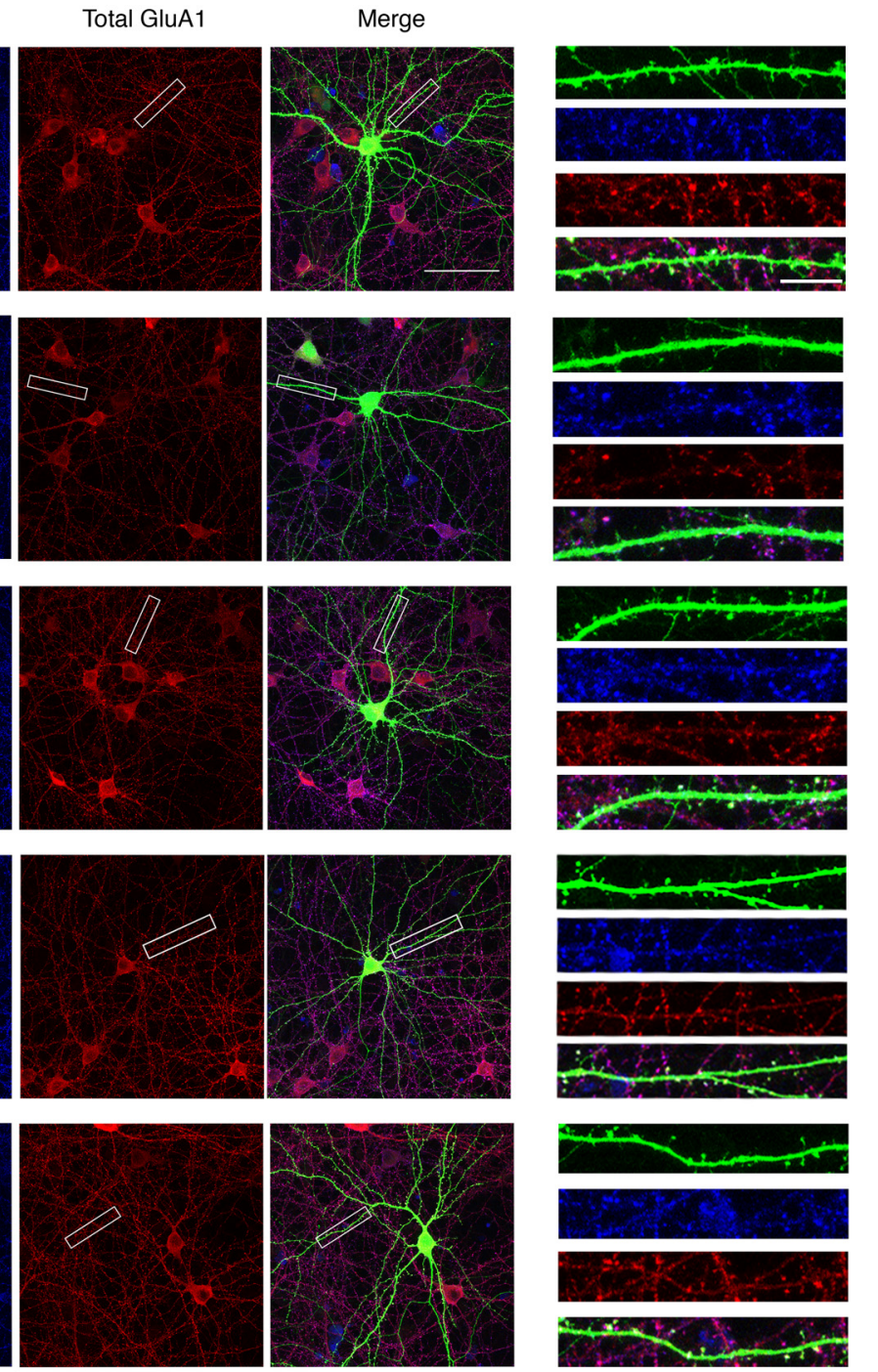
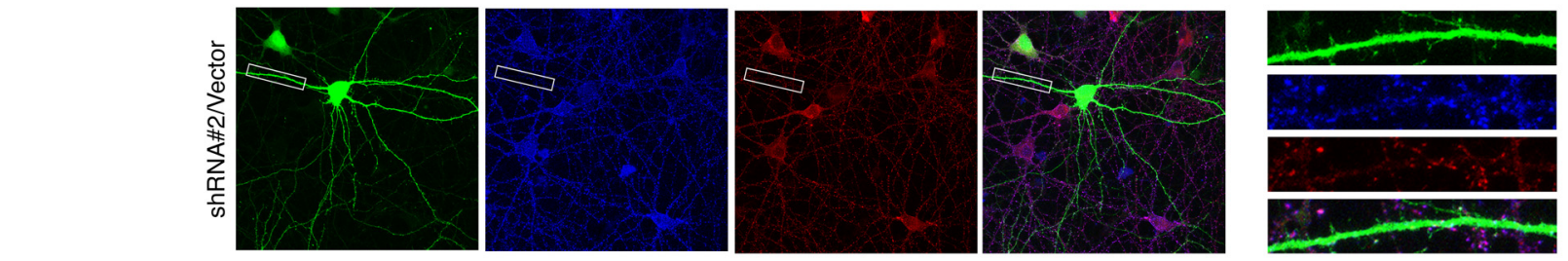
.

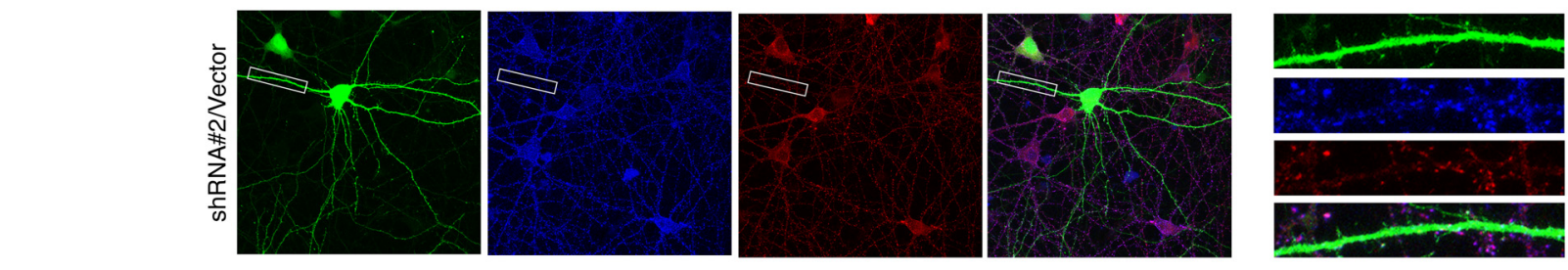
.

\section{.}


A

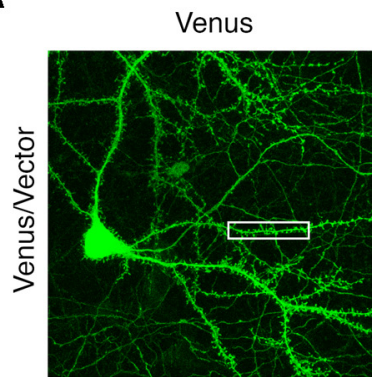

Surface GluA1

Total GluA1

Merge
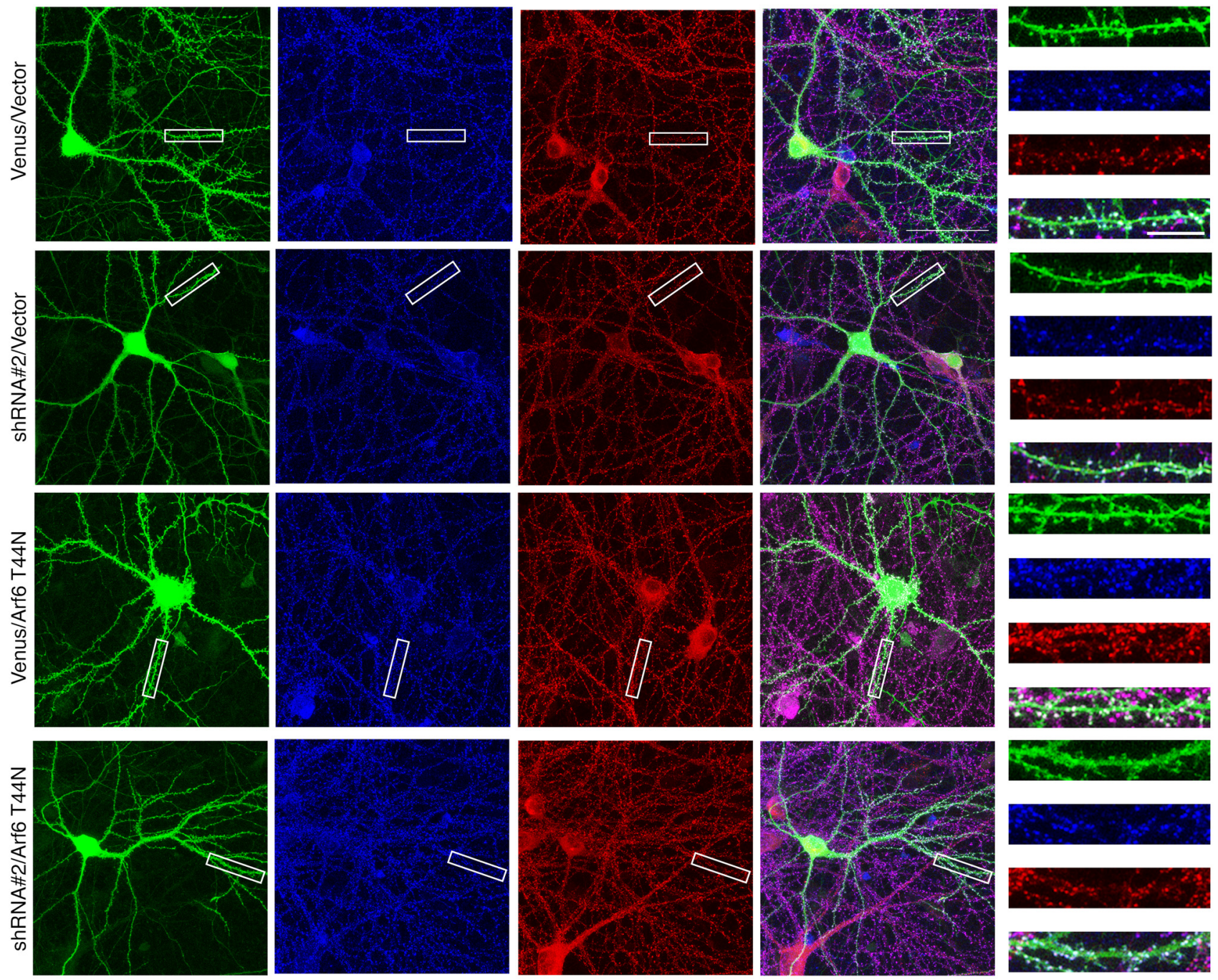

B

Normalized surface GluA1

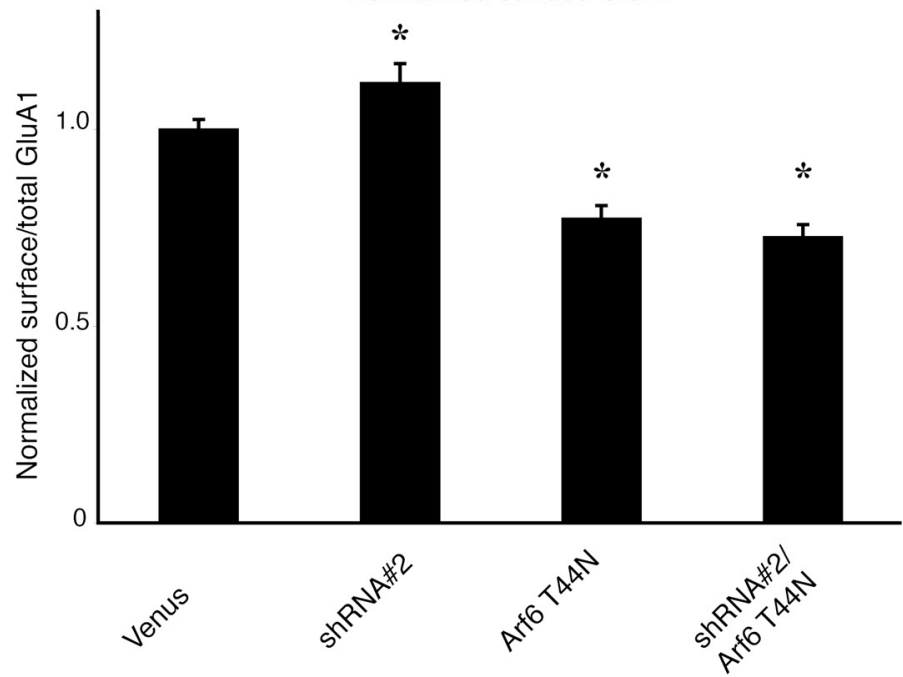

Figure 7. AGAP3 and Arf6 together regulate trafficking of GluA1. A, Representative images of GluA1 in hippocampal staining after cotransfection of AGAP3 shRNA and Arf6 T44N (dominantnegative). Scale bars: 50 and $10 \mu \mathrm{m}$. B, Quantification of surface/total GluA1. One-way ANOVA, $p=2.2-16$, dendritic regions $=128,101,85,87$ from two independent cultures sets. ${ }^{*} p \leq 0.05$ after Tukey's HSD post hoc test compared with vector control. Error bars are standard error of mean. 
A
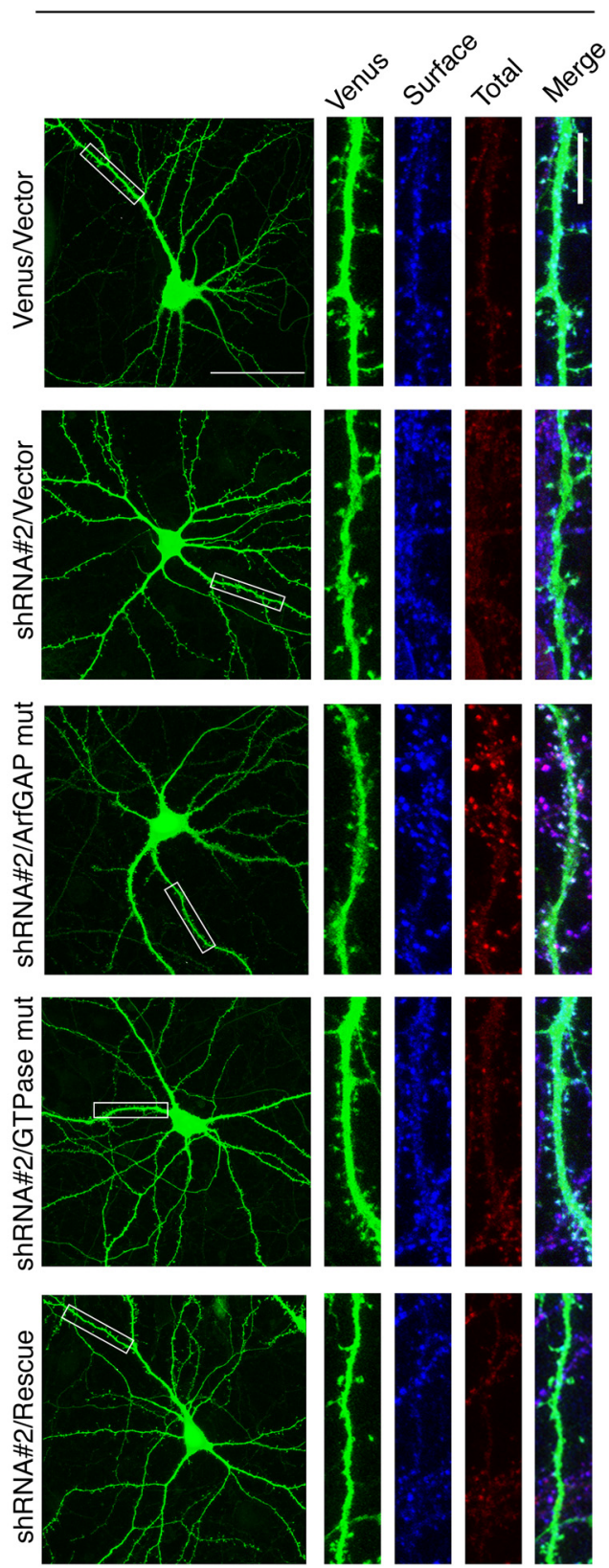

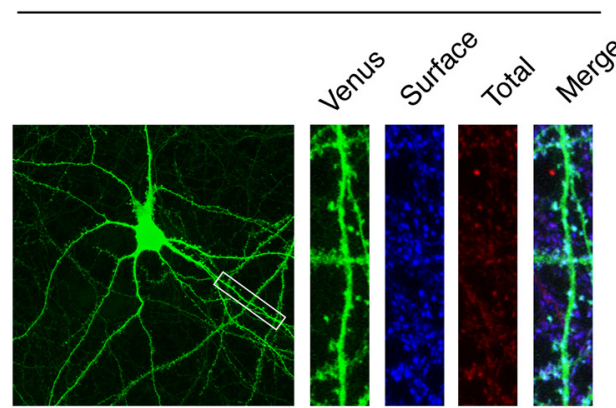

Stimulated
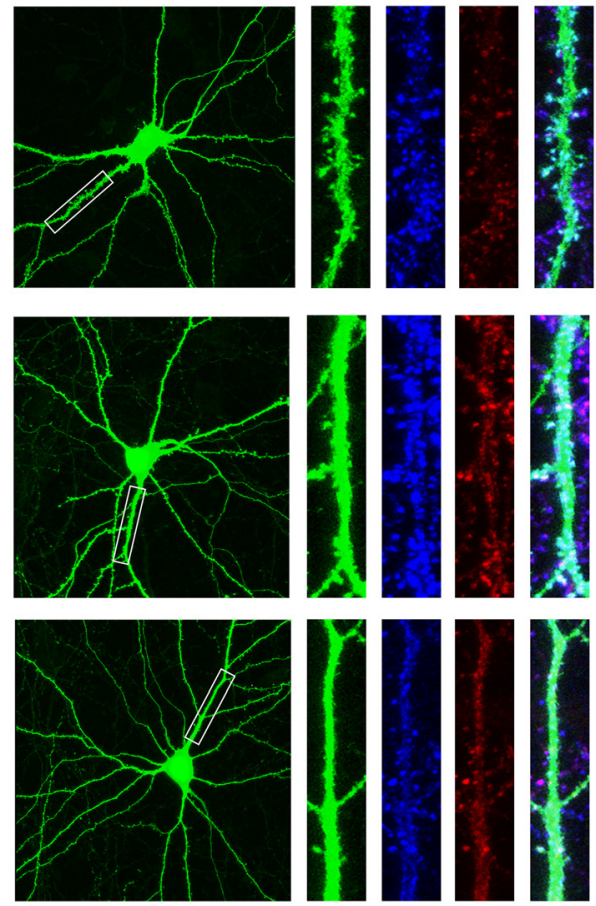

B
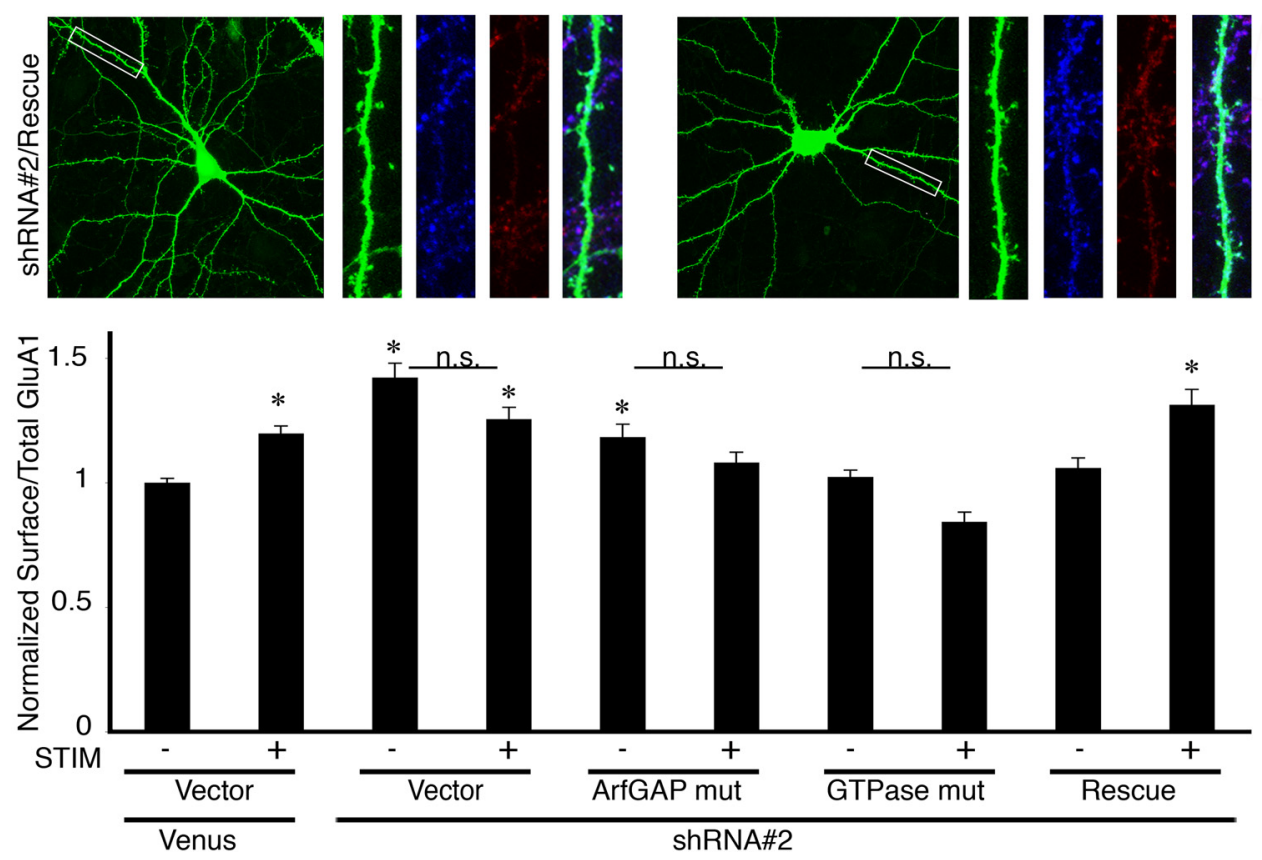

Figure 8. AGAP3 regulates trafficking of GluA1 during chemical LTP.A, Representative images of GluA1 staining with and without chemical LTP in hippocampal cultures cotransfected with AGAP3 shRNA\#2 and AGAP3 rescue constructs insensitive to the knockdown by shRNA\#2. AGAP3 expression is rescued using either AGAP3 WT or the signaling domain mutants (mut). Scale bar: 50 and 10 $\mu$ M. B, Quantification of surface/total GluA1 with and without chemical LTP stimulation. One-way ANOVA, $p=2.2 \mathrm{e}-16$, dendritic regions $=242,313,199,193,238,198,216,198,187,218$ from four independent culture sets. Significant ${ }^{*} p \leq 0.05$ after Tukey's HSD post hoc test is indicated compared with vector control. Error bars are standard error of mean. 
preferentially complexes with SynGAP and SAP102 (Sans et al., 2000; Kim MJ et al., 2005); whereas, NR2A preferentially complexes with PSD95 (Sans et al., 2000). It will be interesting to further investigate the contribution of AGAP3 in subunit-specific signaling through the NMDA receptors.

The experimental results presented in this paper support that AGAP3 is an Arf6 GAP that regulates basal AMPA receptor trafficking. Consistent with this, Arf6 cycling between GTP and GDP bound states regulates membrane and vesicular trafficking and plays an important role in receptor recycling (Donaldson, 2003). Particularly, Arf6 GAPs have been shown to be crucial for recycling Arf6-containing endosomes back to the plasma membrane and for convergence with Rab5-containing recycling endosomes (Donaldson, 2003). Supporting known Arf6 GAP function, knockdown of AGAP3 increased basal levels of active Arf6 and increased AMPA receptors on the cell surface. WT AGAP3 but not the ArfGAP domain mutant could rescue the trafficking defect. In addition, expression of a GDP-binding mutant $\mathrm{Arf6}_{\mathrm{T} 44 \mathrm{~N}}$ blocked the effects of increased surface AMPA receptor resulting from AGAP3 knockdown. Together, these studies show that AGAP3 is an Arf6 GAP that is important for regulating AMPA receptor trafficking during basal conditions.

In addition to regulating Arf6, AGAP3 regulates the Ras/ MEK/ERK signaling pathway that is crucial for trafficking of AMPA receptors during NMDA receptor-dependent LTP (Zhu et al., 2002; Kim MJ et al., 2005; Rumbaugh et al., 2006). In our experiments, we observed an increase in Ras/ERK and Arf6 signaling during NMDA receptor-dependent chemical LTP stimulation. One way this can occur is by relieving AGAP3's inhibition on Ras and/or Arf6 leading to activation of Ras/ERK signaling. In support of this hypothesis, we find similarities in Ras/ERK and Arf6 signaling between AGAP3 knockdown and during chemically induced LTP. (1) Knock down of AGAP3 leads to increased basal Ras and Arf6 activity. (2) Reducing AGAP3 expression during chemically induced LTP leads to occlusion of the increased Ras/ERK and Arf6 activity associated with LTP. (3) Finally, perturbing Ras signaling by knockdown of AGAP3 and molecular replacement with the AGAP3 GTPase mutant blocked activityinduced AMPA receptor trafficking that reflects attenuation in Ras/ERK signaling. Together, these findings suggest that the AGAP3 GTPase domain plays a role in the activation of Ras/ERK signaling and subsequent activity-dependent AMPA receptor trafficking during LTP.

AGAP3 is a novel NMDA receptor interacting protein that functions both in activity-dependent and basal trafficking of AMPA receptors. We have separated the Ras/ERK and Arf6 pathway through AGAP3's signaling domains, GTPase domain, and ArfGAP domain, respectively. What is the relationship between AGAP3 GTPase domain and ArfGAP domain? These observations may reflect the intramolecular regulation of AGAP3's GTPase domain and ArfGAP domain or a complex interdependence between Ras/ERK and Arf6 signaling. Published literature reports that in a closely related protein, AGAP1, the GLD regulates its ArfGAP activity. Binding of another small G-protein, Rho and Rac, to the GLD of AGAP1 increases its ArfGAP activity and Arf specificity (Luo et al., 2012). These findings suggest that similar allosteric regulation may exist for AGAP3, perhaps through SynGAP or Ras. Additionally, a complex interdependent relationship between Arf6 and Ras/ERK is observed. First, Ras and ERK traffic together in Arf6-positive endosomes (Porat-Shliom et al., 2008). Second, Arf6 activation induces phosphorylation of ERK and similarly, activation of MEK/ERK pathway activates Arf6 (Tague et al., 2004; Robertson et al., 2006). Third, expression of dominant-negative $\operatorname{Arf6}_{\mathrm{T} 27 \mathrm{~N}}$ can partially inhibit EGF-induced ERK phosphorylation and inhibition of MEK partially inhibited Arf6 activation (Robertson et al., 2006). These findings reveal that a complex relationship between Ras/ERK and Arf6 signaling exists. Our studies show that AGAP3 is likely involved. At basal state, AGAP3 functions as an Arf6 GAP to regulate steady-state levels of Arf6 activity. Upon NMDA receptor activation, AGAP3 promotes Ras/ERK signaling through its GTPase domain and Arf6 activity is increased. Subsequently, activation of Arf6 and Ras/ERK signaling together increases AMPA receptor surface expression. These findings provide an exciting avenue of study for finding common mechanisms of basal and activity-dependent regulation of AMPA receptor trafficking.

This study strongly supports a novel role for Arf6 as a link between NMDA receptor signaling and AMPA receptor trafficking. Arf6 can signal to not only Ras GTPase, but also regulates actin polymerization (Donaldson, 2003), a process known to be important for spine morphology changes that occur during LTP. It will be interesting to investigate the link between Arf6 signaling and spine morphology during LTP. Furthermore, Arf6 activation has been implicated in mGluR-dependent LTD and NMDA receptor-dependent LTD (Scholz et al., 2010), suggesting that different types of plasticity may converge at regulation of Arf6. These similarities may indicate a common signaling mechanism for various forms of plasticity to regulate Arf6 at different points of its GTPase cycle. Future studies to elucidate common mechanisms in plasticity may provide insight into designing drugs that aid memory-related diseases.

\section{References}

Atkins CM, Selcher JC, Petraitis JJ, Trzaskos JM, Sweatt JD (1998) The MAPK cascade is required for mammalian associative learning. Nat Neurosci 1:602-609. CrossRef Medline

Bendor J, Lizardi-Ortiz JE, Westphalen RI, Brandstetter M, Hemmings HC Jr, Sulzer D, Flajolet M, Greengard P (2010) AGAP1/AP-3-dependent endocytic recycling of M5 muscarinic receptors promotes dopamine release. EMBO J 29:2813-2826. CrossRef Medline

Blum S, Moore AN, Adams F, Dash PK (1999) A mitogen-activated protein kinase cascade in the CA1/CA2 subfield of the dorsal hippocampus is essential for long-term special memory. J Neurosci 19:3535-3544. Medline

Carlisle HJ, Manzerra P, Marcora E, Kennedy MB (2008) SynGAP regulates steady state and activity-dependent phosphorylation of cofilin. J Neurosci 28:13673-13683. CrossRef Medline

Chan CB, Chen Y, Liu X, Tang X, Lee CW, Mei L, Ye K (2011) PIKEmediated PI3-kinase activity is required for AMPA receptor surface expression. EMBO J 30:4274-4286. CrossRef Medline

Chen HJ, Rojas-Soto M, Oguni A, Kennedy MB (1998) A synaptic RasGTPase activating protein (p135 SynGAP) inhibited by CaM kinase II. Neuron 20:895-904. CrossRef Medline

Donaldson JG (2003) Multiple roles for Arf6: sorting, structuring, and signaling at the plasma membrane. J Biol Chem 278:41573-41576. CrossRef Medline

English JD, Sweatt JD (1996) Activation of p42 mitogen-activated protein kinase cascade in hippocampal long-term potentiation. J Biol Chem 271: 24329-24332. CrossRef Medline

English JD, Sweatt JD (1997) A requirement for the mitogen-activated protein kinase cascade in hippocampal long term potentiation. J Biol Chem 272:19103-19106. CrossRef Medline

Grant BD, Donaldson JG (2009) Pathways and mechanisms of endocytic recycling. Nat Rev Mol Cell Biol 10:597-608. CrossRef Medline

Hayashi T, Thomas GM, Huganir RL (2009) Dual palmitoylation of NR2 subunits regulates NMDA receptor trafficking. Neuron 64:213-226. CrossRef Medline

Kamiya A, Kubo K, Tomoda T, Takaki M, Youn R, Ozeki Y, Sawamura N, Park U, Kudo C, Okawa M, Ross CA, Hatten ME, Nakajima K, Sawa A (2005) Disrupted-in-Schizophrenia-1 is required for neuronal migra- 
tion in the cerebral cortex: perturbation by schizophrenia-associated mutation. Nat Cell Biol 7:1167-1178. CrossRef Medline

Kim JH, Liao D, Lau LF, Huganir RL (1998) SynGAP: a synaptic RasGAP that associates with the PSD-95/SAP90 protein family. Neuron 20:683691. CrossRef Medline

Kim MJ, Dunah AW, Wang YT, Sheng M (2005) Differential roles of NR2Aand NR2B-containing NMDA receptors in Ras-ERK signaling and AMPA receptor trafficking. Neuron 46:745-760. CrossRef Medline

Komiyama NH, Watabe AM, Carlisle HJ, Porter K, Charlesworth P, Monti J, Strathdee DJ, O'Carroll CM, Martin SJ, Morris RG, O’Dell TJ, Grant SG (2002) SynGAP regulates ERK/MAPK signaling, synaptic plasticity, and learning in the complex with postsynaptic density 95 and NMDA receptor. J Neurosci 22:9721-9732. Medline

Krapivinsky G, Medina I, Krapivinsky L, Gapon S, Clapham DE (2004) SynGAP-MUPP1-CaMKII synaptic complexes regulate p38 MAP kinase activity and NMDA receptor-dependent synaptic AMPA receptor potentiation. Neuron 43:563-574. CrossRef Medline

Liao D, Scannevin RH, Huganir R (2001) Activation of silent synapses by rapid activity-dependent synaptic recruitment of AMPA receptors. J Neurosci 21:6008-6017. Medline

Lu W, Man H, Ju W, Trimble WS, MacDonald JF, Wang YT (2001) Activation of synaptic NMDA receptors induces membrane insertion of new AMPA receptors and LTP in cultured hippocampal neurons. Neuron 29:243-254. CrossRef Medline

Luo J, Wang Y, Yasuda RP, Dunah AW, Wolfe BB (1997) The majority of $\mathrm{N}$-methyl-D-aspartate receptor complexes in adult rat cerebral cortex contain at least three different subunits (NR1/NR2A/NR2B). Mol Pharmacol 51:79-86. Medline

Luo R, Akpan IO, Hayashi R, Sramko M, Barr V, Shiba Y, Randazzo PA (2012) GTP-binding protein-like domain of AGAP1 is protein binding site that allosterically regulates ArfGAP protein catalytic activity. J Biol Chem 287:17176-17185. CrossRef Medline

Malinow R, Malenka RC (2002) AMPA receptor trafficking and synaptic plasticity. Annu Rev Neurosci 25:103-126. CrossRef Medline

Nedyalkova L, Tempel W, Tong Y, Li Y, Arrowsmith CH, Edwards AM, Bountra C, Weigelt J, Bochkarev A, Park H Structural Genomics Consortium. Crystal structure of the Ras-like domain of CENTG3. PDB ID: 3IHW

Nie Z, Boehm M, Boja ES, Vass WC, Bonifacino JS, Fales HM, Randazzo PA (2003) Specific regulation of the adaptor protein complex AP-3 by the Arf GAP AGAP1. Dev Cell 5:513-521. CrossRef Medline

Nie Z, Fei J, Premont RT, Randazzo PA (2005) The Arf GAPs AGAP1 and AGAP2 distinguish between the adaptor protein complexes AP-1 and AP-3. J Cell Sci 118:3555-3566. CrossRef Medline

Pena V, Hothorn M, Eberth A, Kaschau N, Parret A, Gremer L, Bonneau F, Ahmadian MR, Scheffzek K (2008) The C2 domain of SynGAP is essential for stimulation of the Rap GTPase reaction. EMBO Rep 9:350-355. CrossRef Medline

Porat-Shliom N, Kloog Y, Donaldson JG (2008) A unique platform for $\mathrm{H}$-ras signaling involving clathrin-independent endocytosis. Mol Biol Cell 19:765-775. Medline
Qin Q, Inatome R, Hotta A, Kojima M, Yamamura H, Hirai H, Yoshizawa T, Tanaka H, Fukami K, Yanagi S (2006) A novel GTPase, CRAG, mediates promyelocytic leukemia protein-associated nuclear body formation and degradation of expanded polyglutamine protein. J Cell Biol 172:497-504. CrossRef Medline

R Development Core Team (2008) R: a language and environment for statistical computing. Vienna, Austria: R Foundation for Statistical Computing.

Robertson SE, Setty SR, Sitaram A, Marks MS, Lewis RE, Chou MM (2006) Extracellular signal-regulated kinase regulates clathrin-independent endosomal trafficking. Mol Biol Cell 17:645-657. Medline

Rumbaugh G, Adams JP, Kim JH, Huganir RL (2006) SynGAP regulates synaptic strength and mitogen-activated protein kinases in cultured neurons. Proc Natl Acad Sci U S A 103:4344-4351. CrossRef Medline

Sans N, Petralia RS, Wang YX, Blahos J 2nd, Hell JW, Wenthold RJ (2000) A developmental change in NMDA receptor-associated proteins at hippocampal synapses. J Neurosci 20:1260-1271. Medline

Scholz R, Berberich S, Rathgeber L, Kolleker A, Köhr G, Kornau HC (2010) AMPA receptor signaling through BRAG2 and Arf6 critical for long-term synaptic depression. Neuron 66:768-780. CrossRef Medline

Selcher JC, Atkins CM, Trzaskos JM, Paylor R, Sweatt JD (1999) A necessity for MAP kinase activation in mammalian spatial learning. Learn Mem 6:478-490. CrossRef Medline

Shepherd JD, Huganir RL (2007) The cell biology of synaptic plasticity: AMPA receptor trafficking. Annu Rev Cell Dev Biol 23:613-643. CrossRef Medline

Soundararajan M, Yang X, Elkins JM, Sobott F, Doyle DA (2007) The centaurin gamma-1 GTPase-like domain functions as an NTPase. Biochem J 401:679-688. CrossRef Medline

Strack S, McNeill RB, Colbran RJ (2000) Mechanism and regulation of calcium/calmodulin-dependent protein kinase II targeting to the NR2B subunit of the N-methyl-D-aspartate receptor. J Biol Chem 275: 23798-23806. CrossRef Medline

Tague SE, Muralidharan V, D'Souza-Schorey C (2004) Arf6 regulates tumor cell invasion via the activation of MEK/ERK signaling pathway. Proc Natl Acad Sci U S A 101:9671-9676. CrossRef Medline

Thomas GM, Huganir RL (2004) MAPK cascade signalling and synaptic plasticity. Nat Rev Neurosci 5:173-183. CrossRef Medline

Thompson JD, Higgins DG, Gibson TJ (1994) CLUSTAL W: improving the sensitivity of progressive multiple sequence alignments through sequence weighting, position specific gap penalties and weight matrix choice. Nucleic Acids Res 22:4673-4680. CrossRef Medline

Xia C, Ma W, Stafford LJ, Liu C, Gong L, Martin JF, Liu M (2003) GGAPs, a new family of bifunctional GTP-binding and GTPase-activating proteins. Mol Cell Biol 23:2476-2488. CrossRef Medline

Xia J, Zhang X, Staudinger J, Huganir RL (1999) Clustering of AMPA receptors by the synaptic PDZ domain-containing protein PICK1. Neuron 22:179-187. CrossRef Medline

Zhu JJ, Qin Y, Zhao M, Van Aelst L, Malinow R (2002) Ras and Rap control AMPA receptor trafficking during synaptic plasticity. Cell 110:443-455. CrossRef Medline 